In press at Philosophical Psychology

\title{
Know-How, Intellectualism, and Memory Systems
}

\author{
Felipe De Brigard \\ Department of Philosophy \\ Department of Psychology and Neuroscience \\ Center for Cognitive Neuroscience \\ Duke Institute for Brain Sciences \\ Duke University
}

Correspondence:

Felipe De Brigard

Duke University

203A West Duke Building

Durham, NC 27708-0743

Office: $1+(919)$ 660-3062

E-mail: felipe.debrigard@duke.edu 


\section{Know-How, Intellectualism, and Memory Systems}

Abstract: A longstanding tradition in philosophy distinguishes between know-that and know-how. This traditional "anti-intellectualist" view is so entrenched in folk psychology that it is often invoked in support of an allegedly equivalent distinction between explicit and implicit memory derived from the so-called "standard model of memory". In the last two decades, the received philosophical view has been challenged by an "intellectualist" view of know-how. Surprisingly, defenders of the traditional anti-intellectualist view have turned to the cognitive science of memory, and to the standard model in particular, to defend their view. In this paper, I argue that this strategy is a mistake. As it turns out, upon closer scrutiny, the evidence from cognitive psychology and neuroscience of memory does not support the anti-intellectualist approach, mainly because the standard model of memory is likely wrong. But this need not be interpreted as good news for the intellectualist, for it is not clear that the empirical evidence necessarily supports their view either. I argue that, currently, the philosophical debate is couched in terms that do not correspond to categories in psychological science. As a result, the debate has to either be re-interpreted in a vocabulary that is amenable to experimental scrutiny, or it cannot be settled empirically.

Key words: Knowing-how, Knowing-that, Intellectualism, Declarative Memory, Procedural Memory. 


\section{Introduction}

There is a long-established view in philosophy according to which knowing-how is a fundamentally different kind of cognitive state from knowing-that. Traditionally, philosophers hold this to be a conceptual distinction, for when we say, truthfully, of $S$, that she knows that $p$, we are at the very least asserting a relationship between $S$ and a true proposition, $p$. For example, if I say, of Laura, that she knows that the capital of Venezuela is Caracas, I am at the very least asserting that there is a relationship between Laura and the true proposition stating the fact that Caracas is the capital of Venezuela. By contrast, when we say, truthfully, of $S$, that she knows how to $q$, we need not be asserting that there is a relationship between $\mathrm{S}$ and a true proposition, $q$, for knowing $q$ is neither necessary nor sufficient for $S$ to know how to $q$. For example, if I say, of Joaquin, that he knows how to dance salsa, I need not be saying of him that there is a true proposition he is related to in virtue of which my know-how attribution holds. Joaquin need not know what salsa is, or how it sounds; he may not even need to know that he is dancing salsa when he does it. He may just know how to dance salsa even if he does not know that he's dancing salsa. As a result, it has been customary to say that while knowledge-that is a species of propositional knowledge, knowledge-how is not. This view, often known as anti-intellectualism about knowing-how (henceforth, anti-intellectualism), tends to be attributed to Gilbert Ryle, who sought to "prove that knowledge-how cannot be defined in terms of knowledge-that and further, that knowledge-how is a concept logically prior to the concept of knowledge-that" (1945/1946, p. 4; see also, Ryle, 1949, Ch. 2).

Anti-intellectualism stands in contrast to intellectualism about knowing-how which, in its most general form, holds that knowledge-that and knowledge-how are not fundamentally different kinds of cognitive states (Fantl, 2008). A particular version of intellectualism, which Wallis (2008) dubbed neo-reductionist intellectualism (but I'll just call intellectualism here), has been put forth by Jason Stanley (e.g., Stanley \& Williamson, 2001; Stanley, 2011a, 2011b). According to this view, knowing-how and knowing-that are not different kinds of cognitive states because, in fact, knowing-how is a sub-species of knowing-that (Stanley, 2011a). More precisely, knowing-how is reducible to propositional knowledge because, viz., to know how to $q$ is equivalent to, first, knowing that there is a way to do $q$, and second, knowing it in just the right way, i.e., under a practical mode of presentation.

Since its proposal, there have been a number of arguments against this novel intellectualist view. Some of these arguments, though, are grounded not on a priori discussions about the very concepts of know-how and know-that, but on empirical findings from cognitive psychology and neuroscience. Specifically, a number of philosophers have argued that intellectualism cannot be true because, as a matter of fact, knowledge-how and knowledge-that are two different kinds of cognitive states supported by entirely different cognitive systems. Proponents of this empirical argument latch onto scientific findings purportedly supporting the so-called standard model of memory (SMM), according to which declarative or explicit memory-i.e., a kind of long-term memory that depends on consciousness and is expressed through reports or declarations - is an entirely different cognitive and neural system from non-declarative, implicit or procedural memory-i.e., a kind of long-term memory that does not depend on consciousness and is expressed through performance (Squire, 1988). Since, allegedly, know-that depends on declarative memory alone, and know-how (which they equate to knowledge of skills) depends solely on 
procedural memory, then as a matter of empirical fact knowing-how and knowing-that are fundamentally different cognitive states, and the former cannot be reduced to the latter.

In the current paper I challenge this empirical argument against intellectualism. Specifically, I question the scientific evidence that has been marshalled in support of the distinction between declarative and procedural memory and argue that, upon closer scrutiny, much of the neuropsychological, behavioral and neural evidence that allegedly supports the fact that know-that and know-how are independent is either misconstrued or incomplete. Additionally, I survey new empirical findings that help to strengthen the case that there is no clear distinction between declarative and procedural memory, further weakening the claim that know-that and know-how are distinct. I do so in Section 4, after briefly outlining the main tenets on the intellectualist view (Section 2), and then carefully articulating the empirical argument against intellectualism and its reliance on the SMM (Section 3). However, my response to the empirical argument against intellectualism should not be considered a defense of intellectualism, because - as I argue in Section 5it is not clear that the empirical evidence supports intellectualism either. I further argue that the know-how/know-that distinction, as it is employed in philosophy, does not map onto the distinction between declarative knowledge of facts and procedural knowledge of skills, as it is employed by scientists. At the end, I explore some consequences of this mismatch of distinctions for the intellectualism/anti-intellectualism debate.

\section{Stanley's Intellectualism}

Stanley's argument for (neo-reductionist) intellectualism is two-tiered. The first tier is linguistic (Stanley and Williamson, 2001). It begins by pointing out that contemporary defenders of Ryle's anti-intellectualism rely on superficial syntactic differences between sentences expressing know-how, e.g.,

(1) Joaquin knows how to dance salsa

and sentences expressing know-that, e.g.,

(2) Laura knows that Caracas is the capital of Venezuela

to argue for a fundamental distinction between these two kinds of knowledge (e.g., Bechtel and Abrahamsen, 1991). However, Stanley and Williamson point out that according to current syntactic theory, there are only two relevant syntactic differences between sentences like (1) and (2), viz., unlike the latter, the former contains embedded questions and are untensed. But, they argue, both features are amenable to be treated in terms of know-that. Put it simply, they show how strikingly similar sentences like (1) are to other know-wh- sentences with embedded questions, such as

(3) Efraín knows where to find churros.

(4) María knows when to press the button.

(5) Salomé knows why she's here.

which, as it happens, are all amenable to be rendered in canonical know-that forms (Stanley, 2011a), i.e.,

$\left.3^{*}\right)$ For some place p, Efraín knows that he can find churros at place $\mathrm{p}$.

$\left(4^{*}\right)$ For some time t, María knows that she can press the button at time t.

$\left(5^{*}\right)$ For some reason r, Salomé knows that she is here for reason $\mathrm{r}$. 
Ditto, then, for (1):

$\left(1^{*}\right)$ For some way w, Joaquín knows that he can dance salsa in way w.

Rendering (1-4) as $\left(1 *_{-} 4^{*}\right)$ is not sufficient, though, for under a certain reading it may be possible to interpret a sentence such as $\left(3^{*}\right)$ as being true, while reading (3) to be false. For instance, Efraín may well know, of p, that it is a place to find churros, but he may not know how to get there; he may-to put it differently-know de re, but not de se, that he can find churros at $p$ (Lewis, 1979). Thus, to make (3) and ( $3 *$ ) equivalent it is also necessary that Efraín knows that one can find churros at $\mathrm{p}$ in the right way, that is, under the right mode of presentation. The same goes then for times, $t$, in $\left(4^{*}\right)$, reasons, $r$, in $\left(5^{*}\right)$, and, importantly, for ways, $\mathrm{w}$, in $\left(6^{*}\right)$, which are to be known under a practical mode of presentation. Stanley (2011a, 2011b; also Stanley and Williamson, 2001) acknowledges that it is not easy to fully articulate what a practical mode of presentation is, but-he claims - it is not less easy to articulate than other, less controversial ones, such as demonstrative modes of presentation, which are required to grasp indexical thoughts involving 'I' or 'here'.

Now, the second tier of the argument moves from language to world, for Stanley wants to claim that his "view of the nature of knowing how to do something is a view about the metaphysical nature of these states, and not a view in semantics" (Stanley, 2011a: 143), even if he develops it by way of investigating the linguistic properties of knowledge ascriptions. And the metaphysical conclusion he draws from the linguistic fact that the semantics of know-wh- and know-how ascriptions are unified, and the further fact that all are analyzable in terms of know-that, is that there are no metaphysical differences between states of knowing-how and states of knowing-that. More precisely, he argues that, as a matter of fact, knowing-how and knowing-that are not different kinds of cognitive states, but rather knowing-how is a species or a sub-class of the more general kind of propositional knowledge or know-that. ${ }^{1}$

(Before we continue, let me emphasize that in the current paper I am concerned only with Stanley's version of neo-reductionist intellectualism. In addition to Stanley's, there are currently other arguments for intellectualism that do not rely on linguistic structure but, rather, on the connection between skilled action, intention, and propositional knowledge (e.g., Pavese, 2015a, 2015b, 2018). As far as I can see, nothing of what I say in the current paper affects this other version of intellectualism).

\section{The empirical argument}

In the last decade, Stanley's intellectualism has been challenged. Some challenges deal with the first tier of his argument, either by contending that there are other syntactic differences between know-wh and know-how ascriptions (e.g., Hornsby, 2017), or by arguing that the notion of a practical mode of presentation is particularly problematic (e.g., Glick, 2015). I have nothing to say about this family of arguments. The ones that interest me are those that challenge the second tier of the intellectualist argument on empirical grounds. More precisely, my interest is in an argumentative line put forth by a number of

\footnotetext{
${ }^{1}$ Stanley's argument need not be read as two-tiered. One could read it as inferring - from the linguistic analysis, and from the view that the semantics for know-how ascriptions delivers their truth conditions - that the truth-makers of such ascriptions are cognitive states of propositional knowledge. This reconstruction is probably accurate too. My rendition simply wants to leave open the possibility that one's commitments to the truth-conditions of our know-how ascriptions need not carry ontological weight (I discuss this possibility for propositional attitudes in De Brigard, 2015).
} 
philosophers according to which intellectualism cannot be true because, as a matter of empirical fact, knowledge-how and knowledge-that are two different kinds of cognitive states supported by entirely different cognitive systems.

To buttress this empirical argument, philosophers make use of behavioral and neuroscientific evidence purportedly showing a clear double dissociation between a cognitive/neural system dedicated to encoding, storing and retrieving declarative memories, and a cognitive/neural system dedicated to encoding, storing and retrieving nondeclarative procedural memories. The next step in the empirical argument is to assert, often without much argument, that knowledge-that is either equivalent to —or, at best, depends solely on-declarative memory, whereas knowledge-how is tantamount to - or at best is supported only by-procedural memory. Consequently, partisans of the empirical argument conclude that intellectualism cannot be true, because as a matter of empirical fact knowing-how and knowing-that are two different cognitive states, resulting from two distinct cognitive and neural processes. As such, the former cannot be reduced to the latter.

\subsection{A closer look at the empirical argument}

In one of the first uses of the empirical argument, Wallis (2008) asserts that the beliefs Stanley and Williamson (2001) demand of us in order to have knowledge-how are likely not needed, as evidenced by "the abilities of brain damaged patients to gain knowledge-how despite lacking the ability to form new declarative beliefs" (Wallis, 2008: 140). In support of this claim he cites empirical evidence purportedly demonstrating that individuals with bilateral hippocampal damage — of which patient H.M. is the paradigmatic case- "show a normal or near-normal learning curve" in tasks that involve motor and perceptual skills "despite being unable to form new declarative beliefs" (Wallis, 2008: 133). He further bolsters this assertion by citing a number of classic papers discussing some of the early behavioral and neuroscientific evidence that constituted the backbone of the SMM: an influential framework according to which short-term and long-term memory are different systems, with the latter in turn being sub-divided into declarative and nondeclarative subsystems (Figure 1$)^{2}$. The double dissociation between declarative and nondeclarative memory proves, according to Wallis, that Stanley and Williamson's (2001) intellectualism is "clearly and demonstrably false", because of

...the fact that the brain areas operant in the elicitation and generation of such contextually reliable complexes of dispositions are strongly dissociable from areas of the brain responsible for propositional knowledge. Neurological evidence regarding such behavior clearly implicates areas of the brain other than those associated with propositional knowledge (hippocampus and inferior temporal lobe) in the causal generation of such behavior (e.g. the basal ganglia and the motor areas). (Wallis, 2008: 141)

In turn, this dissociation is supposed to give reason to reject the reduction of knowledgehow to propositional knowledge, since this claim "has always, and rightly, been understood

\footnotetext{
2 To the best of my knowledge, the first time Squire published his now famous diagram, the main split occurred between declarative and procedural memory, which in turn he sub-divided into skills, priming, simple classical conditioning, and other (Squire, 1986). Two years later, and perhaps in an attempt to unify the vocabulary employed by other researchers that contributed to perfect the model, procedural memory became a sub-class of non-declarative memory, covering motor, perceptual and cognitive skills (Squire and Zola-Morgan, 1988). Figure 1 is based on Squire and Zola-Morgan's 1991 diagram, in which procedural memory is now simply called memory for skills and habits.
} 
as requiring that (1) The knowledge itself be propositional knowledge or at least encoded explicitly as particular linguistic or quasi-linguistic expressions that were (2) causally operant in the manifestation of the knowledge." (Wallis, 2008: 141).

Devitt (2011) added his voice to the empirical argument by reviewing human and non-human animal research purportedly demonstrating, once again, a double dissociation between declarative and procedural memory:

[T] he psychological distinction between declarative and procedural knowledge, and the related distinctions about memory and learning, are well established in empirical science. As one researcher says, the evidence for them "lies in experimental data that elucidate various dissociations and differences in performance under different conditions." [Sun, Merrill, and Peterson, 2001] And all of this is evidence for the nature of, near enough, the folk distinction between knowledge-that and knowledge-how. [...] So, if the psychologists are right and procedural knowledge does not involve declarative knowledge, then declarative knowledge is not essential to knowledge-how. (Devitt, 2011:212).

Once again, we find the SMM, and the purported double dissociation between declarative and procedural memory, being used as empirical evidence for the claim that knowledgethat and knowledge-how are two entirely different cognitive states. This evidence, as Devitt concludes, "is very bad news for [Stanley and Williamson, 2001]. Knowledge-that is declarative knowledge. So, psychology shows that procedural knowledge, hence knowledge-how, does not require knowledge-that, precisely what [Stanley and Williamson's] Intellectualism claims it does require. Despite disagreement or uncertainty on many other issues, psychologists speak with one voice on this one." (Devitt, 2011: 213).

The empirical argument is endorsed by Glick (2011) too, when he asserts that "empirical investigation reveals many cases in which creatures possess and exercise knowledge-how but do not possess or appeal to any propositional knowledge-that could constitute the relevant knowledge-how, so knowledge-how cannot be propositional knowledge." (Glick, 2011: 400). Once again, the kind of "empirical investigation" he alludes to comes from research employed in support of the SMM. For instance, he asserts that "data from cases of amnesia have provided much of the justification for the longstanding view in psychology that procedural memory or knowledge is not a kind of declarative memory or knowledge. [...As] paradigm cases of procedural and declarative knowledge map onto paradigm cases of know-how and ordinary knowledge-that, respectively" (Glick, 2011: 401). He even supports the claim that the declarative/procedural memory distinction is tantamount to the knowledgethat/knowledge-how distinction on account that "some well-known articles in the cognitive science literature have explicitly equated the categories" (referring to Cohen and Squire's 1980 paper, which I discuss below). In a nod to Wallis (2008), Glick concludes:

$[\mathrm{N}]$ eurological evidence from studies of memory impairment strongly indicates that the exercise of procedural knowledge and of various sorts of know-how involves brain areas dissociable from the hippocampus and medial or inferior temporal lobe, the brain areas associated with declarative knowledge. [...] Thus, from a scientific point of view it is a well-supported empirical hypothesis that there are two sorts of knowledge, one more practical and skill-related and one more closely tied to ordinary knowledge of facts. Wallis equates the latter with 
" "propositional knowledge", inferring that even if an agent has such knowledge, it need not be "causally operant in the manifestation of [knowledge-how]", contrary to the Intellectualist thesis that one's knowledge of facts plays some crucial role in the exercise of know-how.[...] The case from cognitive science, in essence, is that empirical data shows that know-how can be possessed and exercised even when there is reason to doubt that propositional knowledge is present. (Glick, 2011: 402)

Finally, we find yet another endorsement of the empirical argument against intellectualism, in a more recent paper by Brown (2013). In it, Brown argues that if Stanley's intellectualism is really stating something about the nature of knowing-how, rather than merely about the language of its ascriptions, then "we need to appeal to science to determine whether 'knowing-how' refers to a natural kind of knowledge, [and to] the best scientific characterization of its nature and its relation to other kinds of knowledge" (Brown, 2013: 223). She then latches onto behavioral and neuroscientific evidence put forth in support of the SMM to claim that "procedural knowledge is not a subspecies of declarative knowledge, [and] if procedural knowledge were to be identified with knowinghow and declarative knowledge were to be identified with propositional knowledge, then knowing-how would not be a subspecies of propositional knowledge." (Brown, 2013: 224) As such, she concludes:

[F]rom the perspective of his naturalist critics, Stanley's reconciliation of intellectualism with cognitive science would be seen as an admission that the category of propositional knowledge does not carve the psychological categories at the joints, and that knowing-how is importantly different from cases of declarative knowledge traditionally understood as paradigms of propositional knowledge. (Brown, 2013: 225).

Taken together, and for the sake of simplicity, the variations of the empirical argument I just reviewed (but see also Adams, 2009; Fridland, 2017; Levy, 2017, for more examples) can be captured in the following canonical form:

\section{Empirical Argument}

P1. If knowledge-how is a subspecies of knowledge-that, then there is no fundamental difference in the kind of mental states they are.

$P 2$. Knowledge-how is equivalent to (or, at least, exclusively depends on) procedural memory, whereas knowledge-that is equivalent to (or, at least, exclusively depends on) declarative memory.

P3. But the scientific evidence captured by the SMM demonstrates that procedural and declarative memory are two entirely dissociable and independent systems.

$P 4$. Therefore, there is a fundamental difference in kind between knowledge-how and knowledge-that $(P 2, P 3)$.

$C$. Therefore, it is not the case that knowledge-how is a sub-species of knowledge-that. (Modus Tollens, $P 4, P 1$ )

In the remainder of this paper I argue that the empirical argument is unsound. The first step-in section 4-is to show that $P 3$ is false, as a closer look at the available empirical evidence reveals that the procedural and declarative memory systems are not fully dissociable and independent. Then, in section 5, I argue, first, that said evidence need 
not support intellectualism either and, second, that the best account of the available empirical data is such that the relationship between knowledge-how and procedural memory, and knowledge-that and declarative memory, is neither equivalence nor exclusive dependency, which in turn contradicts $P 2$. But first, it is worth clarifying what the SMM is and what is the evidence in its favor.

\subsection{The standard model of memory (SMM)}

What has come to be known as the SMM was initially suggested over 30 years ago

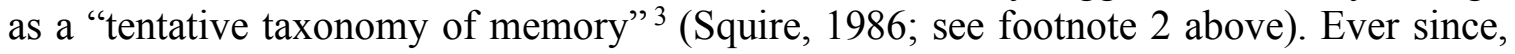
some version of Figure 1 became a must in pretty much every introductory textbook on memory. Why is this model so influential and (seemingly) widely accepted in the scientific community? My sense is that there are both scientific and sociological reasons, the latter having to do with the stature of its main proponent in the neuroscientific community. My main concern here, though, is with the scientific reasons, which led to the belief that the SMM was the best fit for the available evidence unveiled by research on memory and learning in human and non-human animals. Initially, the evidence that the SMM was set to account for came from human pathological data. This "neuropsychological-neural systems approach", as Squire called it, was later supplemented with further behavioral and developmental evidence from human and non-human animals (Squire, 1992). For the purposes of the present paper, however, non-human evidence is going to be less relevant, given the difficulties inherent in understanding the parallels between declarative memory in human and non-human animals. As such, two main lines of evidence for the SMM are critical for the purposes of understanding P3: neural and behavioral evidence from neuropathological patients and neural and behavioral evidence from healthy controls.

[Figure 1]

\subsubsection{Evidence from neuropathological individuals}

No other patient has been as influential for the study of human memory as Henry Molaison, or H.M., as was known until his death in 2008. In 1953, at the age of 27, and after a history of severe epilepsy, William Scoville performed a surgical procedure on H.M. whereby both hippocampi and much of the surrounding medial-temporal lobe (MTL) areas were removed. Four years later, the first post-operative neuropsychological profile of H.M. was published by Scoville and Milner (1957). In it, we were told that H.M.'s IQ improved slightly after the surgery (from 104 to 112) and that "an extensive test battery failed to reveal any deficits in perception, abstract thinking, or reasoning ability" (p. 17), whereas his memory quotient—as measured by Wechsler Memory Scale (Wechsler, 1945)—was very low. It was also reported that while H.M. exhibited complete anterograde amnesia (i.e., incapacity to remember any events that occurred after the surgery), he revealed only partial retrograde amnesia for the three years prior to the surgery.

\footnotetext{
3 The idea that there are different kinds of memory is not new. At least since Aristotle, both philosophers and psychologists have argued for different kinds of memory (De Brigard, 2014a; Michaelian and Sutton, 2017). Memory taxonomies that aimed to fit empirical evidence, however, were less common. In this regard, Squire's SMM was not the only model available at that time. Tulving (1985), for instance, had suggested a different, nested model based upon single, rather than double, dissociations, whereby episodic memory depended (i.e., phylogenetically, ontogenetically, and causally) upon semantic memory, which in turn depended (i.e., phylogenetically, ontogenetically, and causally) upon procedural memory. Nevertheless, the SMM prevailed, despite its strong commitments to double dissociations, in partI think-because it was better suited to fit non-human animal evidence, while also accommodating the evidence accounted for by Tulving's model (for an opinionated historical review, see Squire, 2004).
} 
In the following years, H.M.'s neuropsychological profile became more precise (Milner, Corkin and Teuber, 1968). We were informed, for instance, that his performance in tests that involved reasoning with spatial relationships was within normal ranges, as was his performance in the Wisconsin Card Sorting Test, which is typically employed to measure executive control and strategic planning. It was reported also that H.M. performed normally in several perceptual tasks, including detection of anomalous features in cartoon drawings, tachistoscopic letter recognition, Mooney face perception tasks, and metacontrast masking, among others. Moreover, we were also told that H.M.'s language and working memory, as measured by digit-span recall, were preserved. Such evidence fueled the claim, central to the SMM, that all these cognitive capacities-i.e., perception, working memory, language, abstract reasoning, problem solving - are independent of the hippocampus and surrounding areas in the MTL.

Critically, several post-operatory studies on H.M. seemed to reveal that not all learning was lost, for apparently he was able to acquire new motor skills. At least, this is the notion with which researchers traditionally refer to the kind of learning preserved postsurgically in H.M. The first observation to this effect was reported by Milner (1962), who documented H.M.'s reduction in errors within and across block-trials on a mirror-tracing task. A more comprehensive set of experiments was reported soon after (Corkin, 1968), stating that H.M. was able to improve performance on three motor-learning tasks: rotary pursuit, bimanual tracking, and tapping. Further tests suggested that H.M. was also able to learn perceptual skills, the term employed to categorize a family of tasks including prism adaptation, mirror-reversed words reading and repetition-priming (Gabrieli, 1998).

The observation that perceptual skill learning is preserved in individuals with MTL damage was further supported by consistent results involving similar studies with different amnesic patients (e.g., Cermak et al., 1985; Graf et al, 1984; Moscovitch, 1982; Warrington and Weiskrantz, 1974). More importantly, it seemed as though both perceptual and skill learning were preserved in amnesic patients regardless of the etiology of their impairment. In one of the most influential pieces of evidence in favor of the SMM, Cohen and Squire (1980) reported equivalent performance in a number of motor, perceptual, and primingbased skill tasks on eight amnesic patients with three different etiologies: injury, alcoholinduced Korsakoff syndrome, and after-effect of electro-convulsive therapy. The consistency of these findings, involving different individuals with diverse etiologies, suggested that our capacity to memorize new factual and episodic information-which all patients were severely impaired on - is independent from our capacity to learn new skills which all patients had preserved. Moreover, it also suggested that skill learning did not depend on the hippocampus and surrounding MTL areas, giving researchers further reason to suspect that these two kinds of memory — declarative and procedural—are subserved by two independent and dissociable neural systems:

This distinction between procedural or rule-based information and declarative or data-based information, which is reminiscent of the classical distinction between "knowing how" and "knowing that", has been the subject of considerable discussion in the literature of cognition and artificial intelligence. The experimental findings described here provide evidence that such a distinction is honored by the nervous system. (Cohen and Squire, 1980: 209)

These findings alone do not support the independence of systems postulated by the SMM; at best, they support only a single dissociation between declarative versus short- 
term and non-declarative memories. Nevertheless, partisans of the SMM hold that evidence for double dissociation is also available. Traditionally, the neuropsychological evidence used to support the claim that short and long-term memory systems are independent comes from the study of patient K.F., who exhibited profound deficits in auditory verbal shortterm memory while having no deficits in declarative memory at all (Warrington and Shallice, 1969). To the best of our knowledge, K.F.'s brain damage spared the hippocampus and surrounding MTL areas, as it seem to have affected only his left parietooccipital cortex. Years later, Sullivan and Sagar (1991) offered evidence of double dissociation of short-term and long-term memory for non-verbal material by comparing H.M.'s performance to that of 14 patients with Parkinson's disease - a brain condition that affects the striatum while sparing the MTL. Their results revealed that while H.M. exhibited normal performance in short-term but not in long-term recognition of non-verbal material, the patients with Parkinson's disease showed the opposite pattern of results.

As for neuropsychological evidence of impairments in non-declarative memory with sparing of declarative memory, researchers traditionally invoke cases like patient M.S., who also underwent neurosurgery to alleviate intractable epilepsy, but had only right occipital regions removed (Gabrieli et al., 1995). After the surgery, M.S. scored within normal ranges in standardized tests of attention, memory, language, and reasoning. However, when compared to both controls and individuals with MTL amnesia, M.S. showed no effects of visual priming. Similarly, impairments in motor skill learning with unimpaired declarative memory are reported in patients with basal ganglia disorders - such as Huntington's and Parkinson's disease - as they tend to show marked difficulties with the serial reaction time (SRT) task, as opposed to individuals with MTL amnesia who show normal performance (Clark et al., 2014). Finally, regarding so-called cognitive skills, functional dissociations between amnesic individuals and patients with Parkinson's disease have been reported. For instance, Knowlton and colleagues (1996) showed that while individuals with MTL amnesia were able to learn a probabilistic task known as the weather prediction task, patients with Parkinson's disease never mastered it. However, in a recognition test, Parkinson's patients performed on par with controls, while individuals with amnesia were severely impaired.

\subsubsection{Evidence from healthy individuals}

Although most of the human evidence for the SMM comes from pathological cases, some behavioral and neuroimaging results have also been marshalled in its support. For instance, early neuroimaging studies contrasting retention for short and long-term intervals showed preferential engagement of hippocampus for long-term memory, whereas prefrontal activity was associated with short-term memory (D'Esposito et al., 2000; Talmi et al., 2005). More relevant for our current purposes are experiments purporting to reveal functional dissociations between declarative and non-declarative memory. In the early 1980s, a number of studies showed that manipulating depth of encoding of target itemse.g., focusing on the meaning of a word (deep encoding) versus its font (shallow encoding) - affected only explicit recognition tests, as priming performance was unaffected (e.g., Jacoby and Dallas, 1981). Soon after, Weldon and Roediger (1987) elegantly demonstrated the modal specificity of these priming effects by testing participants with word-completion and free-recall tasks after presenting them with both pictures and words. Their results indicated that while free-recall of pictures was better than for words, word-completion was better for words than for pictures. However, when the 
implicit test included picture-completion tasks, priming for pictures was evident. These and similar studies have been interpreted as evidence that modality and levels of processing (e.g., deep vs shallow encoding) differentially affect explicit tests of declarative memory versus implicit tests of non-declarative perceptual priming. Such differences in processing are thought to provide indirect evidence of distinct neural and cognitive mechanisms engaged in episodic versus perceptual priming tasks (Schacter, Chiu, and Ochsner, 1993).

Dissociations between episodic memory and both conceptual and semantic priming have been documented, too. ${ }^{4}$ In an influential fMRI study, for instance, Wagner and collaborators (2000) showed preferential involvement of left inferior prefrontal cortex during conceptual as opposed to perceptual priming with the same set of stimuli. Importantly, the MTL did not seem to be preferentially involved in either of these tasks. Likewise, semantic priming - which is typically shown by increased speed and response accuracy for words or pictures preceded by semantically related (e.g., "envelope-letter") relative to semantically unrelated (e.g., "broccoli-letter") primes - has been associated with activity in lateral but not MTL regions, which are involved in episodic memory (Rossell et al., 2003). Of note, the behavioral effects of accuracy and speed, as well as the neural effects just mentioned, occur not only in healthy individuals but also in individuals with amnesia, including H.M. and K.C. (Tulving and Schacter, 1990). Together, these and related results suggest that both conceptual and semantic priming recruit regions outside the MTL system, upon which - according to the SMM - declarative memory depends.

Finally, a number of studies in healthy individuals have also reported functional dissociations between declarative and procedural memory. As with neuropsychological patients, one of the most widely studied motor sequence learning tasks is the serial reaction time (SRT). In a typical version of this task, participants see four screen locations, and four response keys that may mimic the spatial arrangement on the screen. On each trial, a stimulus appears in one of the locations of the screen, and the subject is asked to respond with the corresponding key. Trials are usually grouped in blocks of ten or twelve, and accuracy and response times are measured. Critically, the stimuli on the screen appear following a particular sequence repeated from block to block, and normally participants' reaction times become faster as the task progresses even though they are unaware of the recurring sequence. Consistent with results from neuropathological populations, several neuroimaging studies with healthy individuals have shown preferential engagement of premotor and supplementary motor cortices, as well as basal ganglia and cerebellum, during variants of the SRT (Hardwick et al., 2013). By contrast, motor adaptation tasks seem to be more reliant on posterior parietal activity, as its disruption via transcranial magnetic stimulation (TMS) impairs performance (Della-Maggiore et al., 2004).

Perceptual skill learning in healthy populations has also been associated with regions outside the MTL. In a classic study, Poldrack and collaborators (1998) showed changes in neural activation in occipital, inferior temporal, superior parietal and cerebellar regions as a function of learning a mirror reading task. Soon after, Gauthier et al. (1999) reported an association between increased expertise in perceptual categorization of

\footnotetext{
${ }^{4}$ Unlike perceptual priming, which is measured by the increased probability of responding with the same target item as the prime when perceptual features are manipulated (e.g., both seeing and responding "envelope" in a word-completion task like "e_v_1_p_"), conceptual priming refers to the increased probability of responding with the same target item as the prime when the manipulation is conceptual (e.g., responding "envelope" in a recognition test more readily after reading about mail than about food). By contrast, semantic priming is understood as the increased probability of responding, not with the same item as the prime, but with a semantically related one.
} 
objects - both real and non-real (e.g., greebles) — and neural activity in the right fusiform area. As for cognitive skill learning, researchers have also employed fMRI adapted versions of the weather prediction task, the learning of which seems to increase activity in basal ganglia. However, when combined with a pair-associate task, recognition shows increased activity in the MTL (Poldrack et al., 2001). This pattern of results is consistent with the dissociation, discussed in the previous section, whereby patients with Parkinson's disease show poor performance in the weather prediction task but intact recognition of pairassociates, while individuals with MTL amnesia show the opposite pattern.

Taken together, the scientific evidence I just summarily reviewed has traditionally been used in support of the SMM, as it is taken to demonstrate clear double dissociations between, first, short-term and long-term memory and, second, declarative and nondeclarative memory. Moreover, these results have also been taken as evidence that the hippocampus and surrounding MTL areas are uniquely involved in declarative memory, whereas non-declarative memory depends upon distinct brain regions, such as the basal ganglia, and motor and sensory cortices for skill learning and priming (Squire 1988; Gabrieli, 1998). However, as I argue in the next section, a closer inspection of both old and new findings clearly suggests that the evidence is mixed, and that the SMM is a poor fit for a significant number of critical results.

\section{Against the empirical argument}

In this section I discuss three sets of findings and argue that they offer counterevidence against the SMM. First, I argue that if we look closely at H.M.'s actual performance, the picture that emerges does not correspond to the textbook description of his neuropsychological profile. Second, I review some newer findings from neuropathological populations that also contradict some of the main tenets of the SMM. Finally, I survey a number of recent behavioral and neuroimaging findings that are difficult to fit within the standard model. The picture that emerges is one in which the SMM turns out to be an inaccurate representation of the nature of our memory and, more importantly, one in which-contra $P 3$ - declarative and non-declarative memory are neither fully independent nor clearly dissociable.

\subsection{H.M. Revisited}

The first piece of countervailing evidence is not new: it comes from H.M.'s own neuropsychological profile. If one looks closely, the story we learn about H.M.'s performance after the surgery, which allegedly fits perfectly with the SMM is, at best, selective and, at worst, distorted. Consider the claim that he had no retrograde amnesia. According to the initial report (Scoville and Milner, 1957), H.M. exhibited only "partial retrograde amnesia for the three years leading up to his operation", and that "early memories [were] seemingly normal" (p.17). However, a few years later this assessment was modified, and we were told that his "apparent retrograde loss is becoming increasingly difficult to delineate" (Milner, Corkin and Teuber, 1968). Then, employing more precise methods to measure autobiographical memory, Corkin and collaborators conducted more extensive testing on H.M., and reported that "the new data confirm the finding that H.M.'s remote memory impairment is temporally limited, but they extend the limits of the deficit back to 1942, 11 years before the medial temporal lobe resection." (Corkin, 1984: 257). In other words, we are told that H.M. conserves no autobiographical memories from the age of 16 to the age of 27, when the surgery took place. Almost two decades later, the record 
was revised yet again. Employing novel approaches to assess the contribution of episodic and semantic information to autobiographical memory, Schmolck and colleagues (2002) showed that most of the already scarce autobiographical memories from the first 16 years of H.M.'s life were semantic and that most likely he only had two episodic autobiographical memories: one about his first cigarette and one about a plane ride. Certainly, this is not the autobiographical memory of an individual with no retrograde amnesia. More importantly, these results strongly suggest, contrary to the SMM, that intact hippocampi are required for the retrieval of episodic autobiographical memories.

The observation that H.M.'s semantic memory for premorbid facts was preserved does not clash with the SMM, since it claims that once consolidated, semantic memories do not depend on the hippocampus to be retrieved. What the SMM does claim is that an intact hippocampus is required to encode all semantic (as well as episodic) memories. Indeed, this is what textbooks typically tell us: that, after the surgery, H.M. was completely unable to encode new declarative information, whether episodic or semantic. However, the discovery of differential forgetting of episodic relative to semantic autobiographical memory motivated researchers to carefully investigate whether H.M. was able to encode new semantic information - and the results suggest that he was. Inspired by H.M.'s occasional references to current events and TV shows, as well as his capacity to complete crosswords whose cues referred to postmorbid facts, Corkin's group wondered whether the bits of post-operative semantic information H.M. was able to retain were learned declaratively or non-declaratively. Initial research showed, for instance, that when prompted with first names of individuals who reached fame after his surgery (e.g., Ray Charles), H.M. would provide the appropriate last name well above chance, suggesting some retained association between the first and the last name. This association, though, could be explained by non-declarative priming, seemingly preserved in H.M.. But what if the association was, not with a simple name, but with a body of knowledge connected with such celebrities? The answer to this question was provided by an elegant experiment conducted by O'Kane and colleagues in 2004 (Exp. 2). In this experiment, H.M. was shown two names, only one of which named a celebrity. His task was simply to identify which name named a famous person. H.M.'s performance in this task was on par with controls: he correctly identified $92 \%$ of the premorbid names, and $88 \%$ of the postmorbid ones. Critically, after identifying a name as famous, he was asked "why is this person famous?" Impressively, H.M. performed no different than controls for premorbid names, and only minimally worse than controls for postmorbid ones. In fact, he was able to recall very precise information about 12 celebrities that became famous after 1953, and somewhat less precise information about a handful more. The researchers interpreted these results as evidence against the null hypothesis - consistent with the SMM-that H.M. would be unable to retrieve semantic information encoded post-operatively.

H.M.'s postmorbid semantic knowledge was also successfully tested with other recognition-based strategies (Corkin, 2013, Chapter 11), and the results all pointed to the same conclusion: H.M. was still able to learn new semantic facts-although at a much slower pace and with more limits than healthy individuals. Nevertheless, this learning cannot be accounted for exclusively in terms of priming. Instead, Corkin and collaborators argue that H.M.'s preserved capacity to learn new facts is due to semantic memory being organized schematically, that is, as related to semantic information already stored in memory. H.M. seemed to have been able to generate new associations between new and 
old semantic information, albeit slowly and less efficiently than controls. Thus, they argue that although hippocampi may be needed to facilitate the association between semantic information during encoding, it can still occur without them. Critically, this evidence also suggests that, contrary to the dogma accepted by the advocates of the SMM and the empirical argument against intellectualism, H.M. was still able to learn new facts.

Finally - and also crucially for our current purposes - the claim that H.M. showed normal skill learning is overblown and imprecise. By 1965, H.M. was tested at least on three occasions about his performance on tasks that were supposed to tap skill learning. The first, well-known test was reported in 1960 by Brenda Milner using a mirror tracing apparatus. H.M. was asked to trace a figure by looking at the reflection of his hand holding a pen. H.M. completed a total of 39 trials over the course of three days, showing marked improvement as measured by a steady reduction in reaction times and errors. This first observation lead Milner to hypothesize that H.M.'s motor skill learning was preserved. But in 1965, H.M. was tested on a sequential maze-task - both visually (Milner, 1965) and tactually (Corkin, 1965) - with abysmal results. In this task, the subject is given a wooden board with metal bolts arranged in a $10 \times 10$ array, and is asked to find the correct path from the lower left corner bolt to the upper right corner bolt using a metal-head stylus by touching one bolt at a time. If a bolt is in the right path it would make no noise; if it isn't, it would make a loud click. By trial and error a subject would, eventually, find the right path. While controls took on average 17 trials and made approximately 92 errors, H.M. was completely unable to learn the path: after 215 trials and 2,877 errors, testing stopped.

In an attempt to reduce the retrieval effort inherent in the task, Milner and colleagues (1968) tested H.M. again with simpler versions of the board: one with a $6 \times 4$ array and another with a $5 \times 4$ array. This last array, according to the researchers, allowed the finding of the right path to occur within the span of short-term memory. This modification minimized the role of declarative memory in completing the task, thus enabling H.M. to non-declaratively encode the motor-sequence path. However, even with this simple array, H.M.'s performance was very poor. While controls learned the path in less than 20 trials and were able to show errorless performance 24 hours later, H.M. took 155 trials and had to be brought back to criterion every day after that, for 14 days, until the error curve was comparable to controls. Moreover, to further evaluate whether the motor sequence was truly learned, a slightly longer maze which included the just-learned path was presented to H.M. immediately after session 14 in order to test transfer of learning. Contrary to controls, who showed flawless transfer of learning, H.M. showed no evidence of transfer at all. Hence, the results from these first three studies suggest that H.M. showed improved performance in only one of the three skill-learning tasks he was evaluated with (i.e., the mirror-trace task). His performance in all the variations of the motor-sequence maze tasks was either null or significantly compromised.

Corkin was aware of the conflicting evidence regarding H.M.'s alleged capacity to learn new skills. As such, she tested him in three different motor-learning tasks: rotary pursuit, bimanual tracking, and tapping. As mentioned above, her 1968 report of the results is widely cited as showing that H.M. was able to learn all these skills. But a closer inspection at the actual data-indeed, a closer reading at Corkin's own discussion of the results - clearly indicates that this conclusion is unwarranted. Consider the first task: rotary pursuit. In this task, the subject is asked to hold a metal-head stylus in contact with a target point on a rotating metal disk. The objective is to keep the stylus in contact with the target 
point until the disk stops rotating. Although it is true that H.M.'s mean time on the target improved, his performance is significantly worse than that of controls, not only because controls are better from the start, but also because their learning curves are markedly different (Figure 2A). Specifically, as Corkin remarks, while control subjects' performance improves linearly to optimal performance by session 7, H.M.'s asymptotes on Session 4 at half the level of performance of controls. Not knowing the variance in the control group, it is hard to tell, but it is likely that if we were to fit regressors to both learning curves, their slopes would be significantly different from one another-indeed, is not clear that H.M.'s would even be linear. Moreover, the other measure of performance-mean number of contacts - was entirely different between H.M. and controls (Figure 2B). While control subjects began by making lots of contacts with the target and learned to stay on target for longer periods of time, H.M. showed the exact opposite pattern. It is unclear which pattern of errors constitutes a better performance on the task; what is unquestionable, though, is that H.M.'s behavior here is diametrically different from controls.

[Figure 2]

A similar story occurs with H.M.'s performance in bimanual tracking. The apparatus for this task consists of one left and one right rotating discs, each containing a different "track" of about $1 / 4$ inches, visible through a horizontal slit of about 3/8 inches. The subject is asked to hold a stylus with each hand and to keep it in contact with the corresponding track while the disc rotates at a rate of 2,1 or .5 seconds. Corkin only reports the results at the .5 seconds rotation, as controls-but not H.M.-reached optimal performance very quickly at both 2 and 1 second rotations. Since each trial was 20 seconds long, the results depicted in Figure $2 \mathrm{C}$ tells us that controls basically hit ceiling (i.e., optimal performance) by session 7. (Had error bars been plotted we would probably dismiss the slightly lower line as reflecting between-subject noise.) By contrast, H.M. starts off at a much lower point than controls, his improvement is erratic and inconsistent, and he never reaches optimal performance. More dramatic is the difference in performance as measured by the mean number of contacts with the track: while H.M. and control subjects start at almost the exact same level, controls reduce the number of contacts with the track linearly and steadily from session to session. By contrast, H.M.'s performance is almost flat. In fact, his best performance on session 13 is on a par with the second worst performance of the control subjects, on session 2. Clearly, H.M.'s performance in bimanual tracking is markedly different from controls'. Finally, in tapping, subjects are shown a circle divided in sectors and are given a stylus to tap them according to a 4-place sequence. Their task is to tap the sectors, in the proper order, as fast as possible. As with the other two tasks, H.M.'s reaction times were slower than controls, and significantly more so when both hands were tested at the same time. Nevertheless, of the three tasks included in this report, tapping is the only one in which H.M.'s performance was equivalent to controls, as both improved comparably from test to re-test.

Taken together, the extant evidence on H.M.'s performance in motor-skill tasks is mixed. Only in two tasks - mirror-tracing and tapping - is H.M.'s performance on par with controls. In all other tasks H.M. performs significantly worse. Indeed, as Corkin herself suggests, it looks as though H.M. performed better in the two tasks that were less constrained and required less demanding motor skills. When the tasks demanded better motor skills, H.M. either never learned them or never reached the same level of performance as controls. But if the evidence about H.M.'s actual performance on motor- 
skill tasks is so conflicting, why are these results taken to suggest that H.M.'s capacity to learn motor skills was preserved? Part of the reason is that, traditionally, it has been suggested that the discrepancies in H.M.'s performance in motor tasks relative to controls were due to general slowness attributable to long-term effects of his anti-epileptic drugs. However, this explanation is unsatisfactory for at least three reasons. First, the evidence as to whether or not there are significant cognitive effects due to long term anti-epileptic treatments is extremely unclear, with some studies suggesting long-term effects for several cognitive processes including - but not limited to - motor control, and others suggesting no long-term effects at all (Vermeulen and Aldenkamp, 1995). Second, even if there was evidence for slowness specific to motor control, this explanation would still be unsatisfactory, simply because H.M.'s reaction times were sometimes well within the range of that of controls - in fact, some controls were slower than H.M. in the tapping task. And, third, even if we account for the alleged sluggishness in his responses, there are other measures of performance that are markedly worse in H.M. than in controls.

So perhaps what happens is that, traditionally, people have been reading more into these results than the data actually support. Both Milner and Corkin took their results to suggest that H.M. was capable of "acquiring certain motor skills despite a severe impairment in learning other kinds of material" (Corkin, 1968: 262). Nevertheless, they also repeatedly acknowledged that H.M.'s performance was not equivalent to controls in most of the tasks. Indeed, Corkin initially suggested that H.M.'s reduced efficiency in certain motor tasks may have been due to his incapacity to recognize the apparatus from day to day, as well as his inability to remember his previous performance, so he wouldn't be motivated to improve upon it. Moreover, she suggested then (Corkin, 1968: 264) — but also more recently (Corkin, 2013: 159) — that the irregular shifts in the bimanual tracking and rotary pursuit tasks may have been hard to predict for H.M., since "this need to anticipate the future may have required input from declarative memory" (ibid). Consequently, she suggested that H.M.'s severe amnesia and his abnormal performance in certain motor tasks were cumulative, not independent, deficits (Corkin, 1968: 264). True, neither Milner nor Corkin were in the business of model building: their purpose was to generate a precise characterization of H.M.'s neuropsychological profile. Nevertheless, neither then (in 1968) nor later (in 2013, that is) when reflecting upon her results was Corkin convinced that they perfectly conformed to the SMM. Her cautious hypothesis was simply "that different motor skills engage separate cognitive and neural processes, [so it is] possible that the particular brain circuit within the striatum recruited for mirror tracing would not be necessary to perform a different skill-learning task, such as learning a specific sequence of responses" (Corkin, 2013: 163). This claim, though, is very different from endorsing a single underlying system for skills.

In sum, a closer look at the original data strongly suggests that H.M.'s traditional textbook neuropsychological profile, which was supposed to support the SMM, is highly inaccurate. On the contrary, his performance either conflicts or fails to support the SMM. First, H.M. shows profound episodic retrograde amnesia, suggesting - contra the SMMthat a functioning hippocampus is required for retrieving remote episodic autobiographical memories. Second, H.M. was capable of learning new declarative semantic information, which the SMM explicitly forbids. Finally, H.M.'s performance in most motor skill learning tasks was either null or significantly subpar relative to controls, strongly 
suggesting - contra the SMM - that his capacity for normal motor skill learning was compromised. ${ }^{5}$

\subsection{Conflicting neuropathological evidence}

Neuropsychological profiles based on single cases are as accurate as the tests employed to generate them, and they are almost always nuanced and complex. Fortunately, evidence from other neuropathological cases further strengthens the case against the SMM. The first piece of evidence concerns the necessity of functioning hippocampi to retrieve premorbid episodic autobiographical memories. Recall that, according to the standard model, the hippocampus is necessary only for encoding declarative memories. Once consolidated, both episodic and semantic memories are retrieved by brain regions outside of the hippocampal complex. Evidence for this claim was initially supported by two observations: 1) that retrograde amnesia is temporally graded in accordance with Ribot's law (1881) — namely that the more remote a memory is, the more likely it is to survive hippocampal damage - and 2) that the severity of retrograde and anterograde amnesias are correlated. However, 20 years ago, Nadel and Moscovitch (1998) reviewed data from over a dozen studies on retrograde amnesia in individuals who, like H.M., had bilateral hippocampal damage, and showed that both claims are likely false. First, their analysis shows that the temporal gradient of retrograde amnesia is correlated with the severity of the hippocampal damage, so that only individuals with spared hippocampal tissue show retention of premorbid episodic autobiographical memories. When the whole hippocampal formation (i.e., hippocampus, subiculum, and dentate gyrus) is affected, the gradient is minimal, and when the entire hippocampal complex is affected (i.e., hippocampal formation plus entorhinal, perirhinal, and parahippocampal cortices), it is completely flat. Second, retrograde and anterograde amnesia are only partially correlated, for damage to the hippocampus proper is sufficient to generate episodic anterograde amnesia, although it need not generate corresponding retrograde amnesia. Finally, as was the case with H.M., there is evidence of sparing of both retrograde and anterograde semantic memory, indicative of the relative independence of this form of declarative memory from the MTL.

This last point is very important because it speaks not only against the SMMwhich states that the hippocampus is necessary for the encoding of all declarative information - but also the empirical argument, as it assumes that individuals with MTL amnesia are incapable of learning new facts. However, many of the studies reviewed by Nadel and Moscovitch (1997) suggest otherwise. For instance, the patient from Warrington and McCarthy (1988) showed normal memory for the meaning of premorbid and postmorbid words. The same occurred with a group of non-Korsakoff amnesic patients studied by Verfaellie and colleagues (1995), as well as Holdstock et al.'s (2002) patient, who was able to recognize postmorbid celebrities and famous events. But perhaps the strongest piece of evidence in support of the claim that semantic facts can be learned independently of the hippocampus, comes from well-documented cases of developmental amnesia. In 1997, Vargha-Khadem and collaborators reported the cases of Beth, Jon and Kate, all of whom had severe anoxic episodes in their childhood (at birth, 4 y/o, and 9 y/o,

\footnotetext{
${ }^{5}$ Other aspects of H.M.'s “textbook" neuropsychological profile have been questioned too. For instance, it has been suggested that H.M.'s post-operative language was affected (MacKay, Stewart, and Burke, 1998) and that his working memory may have been impaired too, since it was only minimally tested (Ranganath and Blumenfeld, 2005). However, I prefer not to discuss these two observations at length, mainly because the issue about H.M's postmorbid linguistic abilities is very hard to settle (see Corkin, 2013, Ch. 11), and also because the evidence regarding his working memory capacity is too limited.
} 
respectively), leading to sustained hippocampal damage and a profound amnesia. However, their neuropsychological profiles show that despite very low scores in episodic memory tasks, their semantic memory was essentially preserved. Indeed, although incapable of storing new episodic information, all three were able to complete school and went on to live relatively normal lives.

Further studies with neuropathological individuals cast doubt upon other tenets of the SMM. For instance, according to it, short term and long term memory are supported by distinct neural systems, as only the latter depends on the hippocampus. However, recent evidence suggests that while working memory for individual words and digits may be preserved in MTL amnesia, working memory for conjunction of items (Olson et al., 2006), faces and scenes (Hannula et al., 2006), and topographical landmarks (Hartley et al., 2007), is impaired (see Ranganath and Blumenfeld, 2005, for a review). Likewise, contrary to the SMM - according to which perception is independent of the MTL-research conducted in the last couple of decades has shown that individuals with hippocampal damage have difficulty solving perceptual discrimination tasks that involve complex and ambiguous scenes (Barense et al., 2010; Lee et al., 2012). Finally, contrary to SMM claim that the MTL exclusively subserves encoding of declarative memory, recent evidence strongly suggests that individuals with MTL damage have trouble in cognitive tasks outside the domain of declarative memory, such as episodic future (Hassabis et al, 2007) and counterfactual thinking (Mullally and Maguire, 2014), as well as certain tasks involved in social cognition (Laurita and Spreng, 2017) and mind-wandering (McCormick et al., 2018).

What about skill learning? Surprisingly, after H.M., there have been very few studies specifically on skill learning in individuals with amnesia due to bilateral MTL damage. ${ }^{6}$ I already have discussed Cohen and Squire's (1980) influential paper, showing intact learning of mirror-reading skill for non-repeated words in 14 patients. Follow-up studies from Squire's group show similar results in individuals receiving electroconvulsive therapy (Squire et al., 1984). However, once we move away from simple mirror-tracing and mirror-reading tasks, and away from Squire's patients, the evidence becomes murkier. Charness and colleagues (1988), for instance, tested two patients on a novel arithmetic skill and only one of them showed improvement. Years later, Tranel and collaborators (1994) tested a large group of patients on rotary pursuit, mirror-tracing and mirror-reading tasks. However, of these patients, only three had bilateral hippocampal damage (of unknown extent) and their results are difficult to interpret, as they are averaged together with several other patients and control data is not reported. More recently, Heyselaar and collaborators (2017) showed syntactic priming in a group of Korsakoff patients; however, their control group did not show the same effect, complicating the comparison. More strikingly, Döhring and colleagues (2017) tested sixteen patients with transient global amnesia on the finger tapping task ${ }^{7}$. Although their lesions are limited to just one section of the hippocampus, patients did not perform at the same level as controls

\footnotetext{
${ }^{6}$ There are two other studies worth mentioning, one of which is the main topic of section 5 . The other one is a brief report by Yamashita, from 1993, where three patients with bilateral hippocampal damage are compared against six controls in the rotary pursuit task. Unfortunately, this study is severely underpowered, and the variance in the data from both patients and controls is so large that it is almost impossible to interpret.

${ }^{7}$ Transient global amnesia (TGA) is a rare neuropsychological disorder, usually caused by a temporary anoxic lesion to hippocampal neurons in CA1, and it is normally reversible. During the acute phase, which lasts about 24 hours, patients with TGA present a profound amnesic profile, after which they recover back to baseline but without remembering anything of what happened during that period.
} 
either during learning or during re-test within the acute phase. Only when they recovered from their lesion and were tested weeks later were they able to perform normally.

A parallel line of research on neuro-rehabilitation shows similarly complex results. Building upon the kind of neuropsychological studies discussed here, researchers and clinicians have worked on evaluating therapeutic strategies to promote skill learning in individuals who become amnesic. In a pioneering study by Glisky, Schacter and Tulving (1986), four patients with different degrees of memory compromise were trained on very simple computer programing skills. Their results show that although there is learning, it is definitively not on par with controls, as patients took much longer, made more mistakes, and needed constant reminders - in the form of semantic information and instructions - to complete the tasks. Other studies have reported similar results, with learning over time but always qualitatively different and never at the same level as controls (e.g., Kime, Lamb and Wilson, 1996). Finally, to further complicate the picture, recent evidence shows that when we start varying certain parameters of tasks whose performance was thought to be independent of the hippocampus, individuals with MTL amnesia show no learning. For instance, as discussed in section 3.2.2., perceptual skills such as probabilistic learning, often measured with variants of the weather prediction task, are allegedly preserved in hippocampal amnesia. However, recent studies show that varying the parameters of the predictive regularities in the stimuli (Schapiro et al., 2014), or even the timing of the feedback from 1 to 8 seconds (Foerde et al., 2013), is enough to impair statistical learning in individuals with MTL amnesia.

In sum, evidence from neuropathological individuals suggests that many of the core tenets of the SMM are likely false. First, the hippocampus seems to be needed for both the encoding and retrieval of episodic memories. Second, a functioning hippocampus may facilitate but is definitively not indispensable for learning semantic facts. Third, the hippocampal complex is necessary for a number of cognitive processes outside the domain of memory, including - but perhaps not limited to-perceptual discrimination of ambiguous scenes, episodic and counterfactual thinking, and working memory tasks involving spatial and relational information. Finally-and critical for our current purposes - the evidence in support of preserved skill learning in MTL amnesia is meager and complex, not only because it seems consistent for a very circumscribed set of tasks, but also because it collapses when their parameters are minimally altered.

\subsection{Conflicting behavioral and neural evidence}

Thanks to recent developments in behavioral and neuroimaging methods, which allow researchers to explore brain activity associated with different memory tasks, evidence accrued in the last decade and a half overwhelmingly suggests that the alleged cognitive and neural dissociations assumed by the SMM are far from clear. I have already discussed some results showing hippocampal activation during visual and working memory tasks as a function of material, such a relational, conjunctive and spatial information (Ranganath and Blumenfeld, 2005). More recent evidence has also shown hippocampal activation during working memory tasks involving words (Axmacher et al, 2010) and items arranged in 3D-grids (Hannula and Ranganath, 2008). Consistent evidence comes also from single cell recording studies in macaques, showing that certain neural signatures that were thought to index working memory processing can be recorded in entorhinal cortex, suggesting - contra the SMM - that neuronal populations within the 
MTL play a very active role in the maintenance of information for short periods of time (Ranganath and Blumenfeld, 2005).

Neuroimaging evidence also overwhelmingly shows that hippocampal activity is evident during not only encoding but also retrieval of both episodic and semantic memories (Ryan et al, 2008). Additionally, and consistent with the results from patients, a growing number of neuroimaging studies have reported hippocampal and MTL activity during tasks outside the domain of declarative memory encoding, such as episodic future (Addis et al, 2007) and counterfactual thinking (De Brigard et al., 2013), spatial navigation (Eichenbaum and Cohen, 2014), and certain kinds of perceptual tasks (Lee et al., 2012), among others. And this is only the tip of the neuroimaging iceberg, for the evidence strongly suggest that, contrary to the SMM, the hippocampal complex is not uniquely dedicated to the encoding of declarative memory.

But more critical to our purposes is the amount of recent behavioral and neuroimaging evidence showing that the alleged boundaries between declarative and nondeclarative memory are - as some researchers put it — rather "porous" (Dew and Cabeza, 2011). One line of evidence, for instance, has shown significant cognitive and neural overlap between conceptual priming - a process typically associated with non-declarative memory - and familiarity - a process typically associated with episodic memory ${ }^{8}$. What this research has shown is that a frontal N400 effect, previously linked to familiarity, is also linked to conceptual priming (Voss and Federmeier, 2011). Relatedly, fMRI studies have shown significant overlap in rhinal cortex between familiarity and conceptual priming, further suggesting shared mechanisms between the two processes (Fernandez and Tendolkar, 2006). Additionally, a number of experimental results have shown not only that the hippocampus is sensitive to information previously presented relative to new information (Daselaar et al., 2014), but also that it may be needed to encode new relational information, regardless of whether such information was consciously encoded or not (Duss et al, 2014). That the hippocampus is recruited during the encoding of episodic information regardless of whether or not the subject is conscious of it goes against the very definition of a declarative memory system upheld by the SMM.

Finally, there is also plenty of evidence showing that the hippocampus and surrounding MTL areas are involved in the consolidation of motor skill tasks. In a pioneering study, Schendan et al. (2003) showed increased hippocampal activity on a SRT task learned both implicitly and explicitly, relative to a control condition of random sequence blocks. More recently, Albouy and colleagues (2008) showed the involvement of the hippocampus in the consolidation of a different motor sequence task, known as the serial oculomotor reaction time (SORT) task - whereby dots appear, one at a time, in one of four possible locations with sporadic changes of color. Participants are asked to detect color changes. However, unbeknownst to them, the transition of dots follows an ordered sequence, very much in the spirit of the SRT task. Their results showed not only that the

\footnotetext{
${ }^{8}$ Many researchers believe that episodic memories are retrieved by the combination of two relatively distinct subprocesses: recollection and familiarity. The former is characterized as the slow, intentional retrieval of the richly contextual spatiotemporal information that constitute the content of our episodic memories, whereas the latter is a fast, unintentional retrieval of the general gist of the event that brings about a sense of having occurred in one's own past. Moreover, there is now evidence of underlying neural distinctions between the two processes: while recollection has been associated with activity in the hippocampus proper, and has been indexed by posterior late positive components using event-related potentials (ERP), familiarity has been associated with activity in the rhinal cortex and with anterior early negative ERP components (Skinner and Fernandes, 2007)
} 
hippocampus was recruited during learning but also that a hippocampus-striatum collaboration overnight is required for the successful consolidation of the memory for the motor sequence. These, along with the aforementioned results, only scratch the surface of a large body of evidence suggesting significant overlaps in the mechanisms involved in declarative and non-declarative memory.

\subsection{Reassessing the empirical argument}

Taken together, the neuropsychological, behavioral, and neuroimaging evidence reviewed in this section strongly suggests that many core tenets of the SMM are likely false. First, it is not the case that the hippocampus and surrounding MTL areas are required only for the encoding of declarative memories: as it turns out, these structures are also required to retrieve episodic memories. Second, the idea that the hippocampus is no longer necessary after an episodic memory has been consolidated is also wrong: functioning hippocampi seem indispensable to retrieve detailed episodic autobiographical memories regardless of their age. Third, the evidence also suggests that the hippocampus may not be indispensable for encoding semantic information. Fourth, contrary to the SMM claim that the hippocampus is exclusively involved in encoding declarative information, the evidence reveals that it is critical for a number of operations outside the memory domain. Fifth, and relatedly, this evidence also shows that a functioning hippocampus may be required for learning certain tasks thought to index skill learning. Finally, some of the most recent results suggest that processes associated with declarative memory (e.g., familiarity; conscious relational memory) share cognitive and neural mechanisms with processes associated with non-declarative memory (e.g., conceptual priming; unconscious relational memory).

The scientific importance of this counterevidence against the SMM is unquestionable. In fact, the research community slowly but steadily has come to realize that this old model of memory is profoundly inaccurate, and a number of alternative models have been offered instead (Redder et al, 2009; Henke, 2010; Cabeza et al, 2018). But more important for our current purposes, this counterevidence has profound philosophical consequences for the debate about intellectualism and anti-intellectualism about knowinghow, as it clearly speaks against $P 3$ of the empirical argument. Specifically, it shows that there is no clear distinction between a declarative and a non-declarative system as stipulated by the standard model. Moreover, the reviewed evidence speaks against specific empirical claims made by philosophers who support the use of the empirical argument against intellectualism. For instance, we have seen that it is false that H.M. "shows a normal or near-normal learning curve" in tasks that involve motor skills (Wallis, 2008: 133), or that he was "unable to form new declarative beliefs" (Ibid.) - if "declarative belief" is cashed out in terms of declarative (semantic) memory. Likewise, it is also not true that "the exercise of procedural knowledge [...] involves areas dissociable from the hippocampus and medial temporal lobe" (Glick, 2011: 402) or that "psychologists speak with one voice" when stating that declarative and non-declarative knowledge are distinct (Devitt, 2011: 213): They don't. The SMM is inaccurate, and while the scientific evidence about the relationship between the mechanisms underlying skill learning and declarative memory is inconclusive and complex, one thing is clear: that if - as $P 2$ states - knowledge-that is tantamount to declarative memory and knowledge-how is tantamount to procedural memory, then - contra Cohen and Squire (1980) - such distinction does not seem to be honored by the nervous system. 
Advocates of the empirical argument may still want to defend a version of it on account that even if H.M. and other individuals with MTL amnesia could still learn new semantic facts, the kinds of facts that matter for intellectualism are not semantic: they are episodic. There are at least two problems with this reply: 1) The brain regions that philosophers have associated with the kind of propositional knowledge required for intellectualism (i.e., medial and inferior temporal lobes [Wallis, 2008; Glick, 2011]) areas we just saw-fundamentally involved in semantic memory. 2) Why should we accept that the kind of propositional knowledge relevant for intellectualism is episodic rather than semantic? An argument against intellectualism along these lines would need to show that the nature of the propositional knowledge it assumes is, in fact, episodic, not semantic. Alas, such an argument is not in the offing. Another possibility is to claim that, despite what the researchers say, H.M. and other MTL amnesiacs learn factual knowledge nondeclaratively. But this move backfires, for it would mean that the format of factual knowledge is such that it can be handled by the non-declarative system, which is the same system that handles procedural memory - a claim that undermines $P 2$.

Finally, another possibility is to focus on the kind of procedural learning H.M. and other individuals with MTL amnesia were able to achieve, and suggest that only those tasks really index skill learning, whereas the other tasks, which were though to measure skill learning, actually do not. The problem with this post hoc response is that it makes the relationship between the experimental tasks and the folk-psychological notion of skill much more mysterious than it already is. Is it true that our folk-psychological notion of skill includes finger tapping but excludes rotary pursuit? Does the concept of skill apply to learning the weather prediction task when the feedback is given within two seconds but not when it is given within ten? I seriously doubt that what we ordinarily mean by skill neatly coincides with precisely the kinds of tasks, in precisely the sorts of conditions, in which individuals with amnesia can reach performance equivalent to controls.

\section{Intellectualism vindicated?}

In section $4 \mathrm{I}$ argued that the scientific evidence does not support the empirical argument against intellectualism, mainly because $P 3$ is false. Does this mean that the empirical evidence supports intellectualism instead? In a recent article, Stanley and Krakauer (2013) defend the claim that motor skills depend on knowledge of facts. In this a paper, they briefly discuss the results of a study by Roy and Park (2010) in a way that could be interpreted as providing evidence in favor of intellectualism. However, this interpretation is far from clear. On the one hand, if one interprets the claim that motor skills depend on knowledge of facts within the dialectic of the empirical argument-i.e., as accepting $P 2$ - then the Roy and Park study do not offer convincing evidence to the effect that declarative memory is necessary for motor skills. But, on the other hand, if - as Stanley and Krakauer seem to suggest - one reads the claim that motor skills depend on the knowledge of facts outside of the dialectic of the empirical argument-i.e., as rejecting $P 2$ - then it is not clear how to interpret such a claim empirically.

The interesting but complex study by Roy and Park (2010) involves one patient, D.A., with severe bilateral hippocampal damage due to herpetic encephalitis, as well as six matched controls. According to the authors, the purpose of the study was "to investigate whether D.A.'s acquisition of novel complex tool knowledge was spared like his procedural memory or impaired like his declarative memory" (Roy and Park, 2010: 3029). 
To that end, they built 15 novel complex tools - 10 targets and 5 lures — using a children's construction toy. Each tool was associated with a particular recipient (e.g., plastic wheel) with which it could interact toward a particular goal (e.g., move the wheel down a path). The study consisted of three 2-hour sessions (S1, S2, S3). There were three days between S1 and S2, and three weeks between S2 and S3. Additionally, each session had three phases: pre-test, training, and post-test. Memory was measured with four tests: a recall test in which participants were shown black and white pictures of the tools and were asked to remember details about them; a recognition test administered also with pictures of the tools; a grasp-to-command test, in which participants were asked to show how to hold the tool if they were going to use it; and a use-to-command test in which participants were asked to demonstrate how to use the tool. As such, the first two measured declarative memory, while the latter two evaluated procedural memory.

[Figure 3]

The experiment proceeded as follows. During S1 pre-test, participants were presented with the tools, and received all four tests. As expected, both D.A. and controls performed at floor, since they've never encountered such tools before (Figures 3A-B). Then they received the training, in the form of an instructional video followed by a demonstration and practice, until the participant was able to perform the task without making any errors within 90 seconds. Here, the results show that both D.A. and controls have comparable mean completion times (Figure 3D). Then, after a short delay involving in a distracting activity, participants received a post-test, identical to the pre-test. As shown in Figures 3A and 3B, during post-test D.A. performs at floor in the use-to-command task (and also in the grasp-to-command task, which isn't depicted), whereas controls are able to complete the task in about 50 seconds with almost $80 \%$ accuracy. In S2 the procedure was just as in S1. Here, however, we see controls performing much better during the pretest than D.A., whose performance remains at floor. Completion time during training was, nevertheless, equivalent between the two (Figure 3D). Yet, after training, only controls showed improved performance; D.A. remained at floor. S3, however, included two variations relative to $\mathrm{S} 1$ and $\mathrm{S} 2$ (Figures $3 \mathrm{~A}-\mathrm{B}$ ). First, the researchers included a recipientcue $(\mathrm{RC})$ use-to-command trial for D.A. immediately prior to post-test. In this trial, unlike all other use-to-command trials, the experimenter placed the recipient in the appropriate position for each tool. The second change was to administer the declarative tests (i.e., the recall and recognition tests) immediately after the $\mathrm{RC}$ trial, rather than before the procedural tests, as was done in S1 and S2. These changes significantly altered D.A's performance in two important respects. First, the RC trial improved his completion time and accuracy during the use-to-command post-test so that his performance was no different than controls. However, no such gain was observed for the other procedural task, i.e., grasp-to-command. Second, having the RC trial immediately prior to the functionalassociative recall tests, in which subjects were asked about the function of the tool and the appropriate position of the recipient, improved DA's accuracy so that it was no different than controls (Figure 3C). However, no such improvement was evident for the other tests of declarative memory, i.e. recognition and recall tests of perceptual and functional features of each tool.

Stanley and Krakauer's brief discussion of the Roy and Park study seems to focus on S1 and S2, as they rightly point out that, unlike controls, D.A. was unable to even begin to use the novel tools in the pre- and post-tests. They also remark that he was able to 
improve performance during training, but only if explicit instruction was provided throughout. Moreover, they point out, that this is no different from the way in which H.M. performed. Unless instruction was provided each day, prior to each task, H.M. would not even know how to begin the task. Consequently, they argue that neither D.A. nor H.M. was really able to perform motor skills, for unless they knew facts about what to do in the motor skill task, they would not have been able to perform it. All H.M. and D.A. show is improvement in motor acuity, not that they learned a new motor skill, for the latter at the very least requires knowing certain facts, such as what to do in order to initiate the task. So, they claim, motor skill depends on knowledge of facts.

How shall we interpret this claim? Their suggestion is that motor skill is a complex process involving two components: the purely procedural aspect of motor acuity and a "knowledge component" (Stanley and Krakauer, 2013: 8). Prima facie, the point Stanley and Krakauer seem to be making appears to be merely semantic. After all, both Milner and Corkin repeatedly acknowledged that H.M. needed to be reminded of the nature of the task immediately prior to testing, which clearly indicates that they did not consider this explicit, task-related information to be constitutive of the performance they were trying to measure. Therefore, one may be tempted to read Stanley and Krakauer as merely trying to correct the historical record by making the point that what Milner and Corkin were measuring should have been called "motor acuity" rather than "skill". Upon reflection, though, I think we should interpret Stanley and Krakauer as arguing — as did I in section 4-against the SMM rather than the actual neuropsychological observations of Milner and Corkin. After all, Stanley and Krakauer are quite right that many researchers, especially in philosophy (as we saw in section 2), have taken the SMM's interpretation of H.M. and similar MTL patients' data as demonstrating that the whole process of skill learning - above and beyond motor acuity - is completely independent of our capacity to remember facts about the relevant motor skill tasks.

That being said, it is still worth wondering what they mean by the "knowledge component", whether or not it is truly necessary for motor skill, and whether or not such a component, when combined with motor acuity, suffices for motor skill. In philosophical fashion Stanley and Krakauer define knowledge as, "minimally, a state with propositional content, one that is suitable for use in guiding action." (Stanley and Krakauer, 2013: 1) The question now is whether we should interpret this "state with propositional content" as a declarative memory, the way in which partisans for the empirical argument interpret it (i.e., in agreement with $P 2$ ), or whether we should construe it in some other way. Let's explore the first option first, and assume that the knowledge component in Stanley and Krakauer's account is to be understood as a declarative memory. Would the Roy and Park study provide evidence for the claim that knowledge of facts, i.e., declarative memory, is necessary for motor skill? My sense is that the results of S3 speak against this interpretation. For one, D.A. was able to reach normal performance in the task, without verbal instruction, when he as given the tool with the receptacle in the appropriate position, as in the RC trial. Was this change sufficient to trigger in D.A. a declarative memory about what to do to initiate the task? Alas, the evidence does not support that interpretation, for we don't see an equivalent increase in performance in his declarative tests. Moreover, as shown in S1 and S2, if D.A. engages in a distraction task right after using the tool, and then receives it with the receptacle in the wrong position, he is unable to complete the task. This suggests that whatever information he was holding in working memory, and in virtue of 
which he was able to initiate the action and even answer two basic questions about the task, was not subsequently consolidated into declarative memory. Whatever "knowledge" allowed him to perform the task during RC in S3 was fleeting and likely non-declarative. ${ }^{9}$

The alternative is to reject $P 2$ and to interpret knowledge of facts outside the dialectic of the empirical argument, that is, as not corresponding to declarative memory. Indeed, this seems to be precisely what Stanley and Krakauer advocate, when they claim that "just as it is a mistake to identify declarative knowledge with knowledge, it is a mistake to identify procedural knowledge with skill" (Ibid: 3 ). However, if we reject P2, and agree that the epistemological distinction between knowing-how and knowing-that does not map onto to the scientific distinction between procedural and declarative memory, then it is unclear how empirical results can provide evidence in favor of intellectualism. One possibility, consistent with Krakauer and Stanley (2013) as well as Pavese (2018), requires us to think of know-how in different terms from the way in which partisans of the SMM have thought of skill. Specifically, it asks us to think of know-how, which is characteristically manifested in terms of intentional actions, as essentially requiring an epistemic state akin to how epistemologists think of knowledge. This alternative intellectualist view of know-how could potentially fit the scientific evidence better, but only insofar as we can provide an empirical interpretation of what the knowledge requirements amount to. And my sense is that, to get to that point, we would require further work to clarify how these terms should be operationalized in order to be empirically tractable (see, Pavese, this issue, for a step in this direction).

\section{Conclusion}

Some philosophers have employed variants of the empirical argument to support anti-intellectualism about knowing-how. In this paper I argued against this strategy, not only because the SMM is inaccurate, but also because the empirical evidence about the relationship between declarative and non-declarative memory is messy and inconclusive. In addition, I argued against interpreting "knowing facts about a motor skill task" as being tantamount to having declarative memories about said task. To be sure, I am not claiming that the argument between intellectualism and anti-intellectualism ought to be settled empirically. My argument is simply that if we are going to look at the sciences for evidence either in favor or against one of these views, we will first have to recognize that the actual relationship between knowledge-how and procedural memory, and knowledge-that and declarative memory, is neither equivalence nor unique dependency. As such, "knowinghow" and "knowing-that" join the ever-growing set of folk-psychological notions that do

\footnotetext{
${ }^{9}$ Roy and Park's motivation to include the RC trial in S3 stems from the observation that during S1 and S2 D.A. "made comments suggesting that he knew the function of the tool, but that he did not know how to position to recipient appropriately" (Roy and Park, 2010: 3031). Similar observations can be found in Corkin's report of H.M.'s performance. She reports, for instance, that "at the begging of Rotary-Pursuit and Bimanual-Tracking test session he was allowed to look at the apparatus and then asked to describe the task. His memory for the Rotary-Pursuit task, though somewhat inaccurate, was consistent in specifying that he had to touch the stylus to the target in order to stop the disc from turning. On one occasion he further stated that he was not supposed to "touch that spring part" on the stylus, something that he had in fact been reminded about several times before. H.M.'s description of the Bimanual-Tracking task was consistently accurate from Session Ill on." (Corkin, 1968: 264). Corking called the retention of this fragmentary information "testing habits", and although she did not elaborate on the nature of this retention, it is consistent with her view that H.M.'s capacity to remember information about the task may have contributed to his performance, just as his deficits in remembering it may help to explain why his performance was never optimal.
} 
not transparently correlate with constructs in cognitive psychology and neuroscience (De Brigard, 2006; 2014b). ${ }^{10}$

\section{References}

Adams, M. P. (2009). Empirical evidence and the knowledge-that/knowledge-how distinction. Synthese, 170(1): 97-114.

Addis, D. R., Wong, A. T., \& Schacter, D. L. (2007). Remembering the past and imagining the future: common and distinct neural substrates during event construction and elaboration. Neuropsychologia. 45: 1363-77.

Albuouy, G. et al., (2008). Both the Hippocampus and Striatum Are Involved in Consolidation of Motor Sequence Memory. Neuron, 58(2): $261-272$

Axmacher, N., Henseler, M. M. et al. (2010). Cross-frequency coupling supports multi-item working memory in the human hippocampus. PNAS, 107(7): 3228-3233.

Barense M. D., Rogers T. T., Bussey T. J., Saksida L. M., \& Graham K. S. (2010). Influence of conceptual knowledge on visual object discrimination: insights from semantic dementia and MTL amnesia. Cerebral Cortex, 20: 2568-82

Bechtel, W. \& Abrahamsen, A. (1991). Connectionism and the mind. Wiley-Blackwell.

Brown, J. (2013). Knowing-how: linguistics and cognitive science. Analysis, 73 (2):220 - 227

Cabeza, R., Stanley, M. L., \& Moscovitch, M. (2018). Process-specific alliances (PSAs) in cognitive neuroscience. Trends in Cognitive Sciences.

Charness, N., Milberg, W., \& Alexander, M. P. (1988). Teaching an amnesic a complex cognitive skill. Brain and Cognition, 8(2), 253-272.

Clark, G. M., Lum, J. A. G., \& Ullman, M. T. (2014). A meta-analysis and meta-regression of serial reaction time task performance in Parkinson's disease. Neuropsychology, 28(6): 945-958

Cermak, L. S., Talbot, N., Chandler, K., \& Wolbarst, L. R. (1985). The perceptual priming phenomenon in amnesia. Neuropsychologia, 23, 615-622.

Cohen, N. \& Squire, L. R. (1980). Preserved learning and retention of pattern analyzing skill in amnesia: Dissociation of knowing how and knowing that. Science, 210: 207-209

Corkin S. (1965) Tactually-guided maze learning in man: Effects of unilateral cortical excisions and bilateral hippocampal lesions Neuropsychologia. 3: 339-351.

Corkin, S. (1968). Acquisition of motor skill after bilateral medial temporal-lobe excision Neuropsychologia. 6: 255-265.

Corkin, S. (1984). Lasting consequences of bilateral medial temporal lobectomy: Clinal course and experimental findings in H.M. Seminars in Neurology, 4(2): 249-259.

Corkin, S. (2013). Permanent present tense: The unforgettable life of the amnesic patient H.M. Basic Books.

De Brigard, F. (2006). Capas limítrofes y dominios de evidencia en ciencia cognitiva. Universitas Philosophica. 46: 53-77.

De Brigard, F. (2014a). The nature of memory traces. Philosophy Compass. 9(6): 402-414.

\footnotetext{
${ }^{10}$ I wanted to thank the audiences of the Workshop on Memory and Skill (Duke, 2016), the Instituto de Investigaciones Filosóficas (UNAM, 2016), and the departments of philosophy at the Universidad Nacional de Colombia (2017) and Tufts University (2018). Special thanks to Carl Craver, Jackie DeRosa, John Krakauer, Bryce Gessell, Paul Henne, Bryce Huebner, Kirk Michaelian, Carlotta Pavese, and Walter Sinnott-Armstrong for comments on previous drafts.
} 
De Brigard, F. (2014b). The Anatomy of Amnesia. Scientific American Mind. 25(3): 39-43.

De Brigard, F. (2015). What was I thinking? Dennett's Content and Consciousness and the reality of propositional attitudes. In: Muñoz-Suárez, C.M. \& De Brigard, F. (Eds.). Content and Consciousness Revisited. N.Y. Springer. pp. 49-71.

De Brigard, F., Addis, D., Ford, J.H., Schacter, D.L., \& Giovanello, K.S. (2013) Remembering what could have happened: Neural correlates of episodic counterfactual thinking. Neuropsychologia.51(12): 24012414.

D’Esposito, M., Postle B. R, \& Rypma, B. (2000). Prefrontal cortical contributions to working memory: evidence from event-related fMRI studies. Experimental brain research. 133:3-11.

Della-Maggiore, V., Malfait, N., Ostry, D. J., \& Paus, T. (2004). Stimulation of the posterior parietal cortex interferes with arm trajectory adjustments during learning of new dynamics. Journal of Neuroscience. 24(44): 9971-9976.

Devitt, M. (2011). Methodology and the nature of knowing how. Journal of Philosophy, 108(4): 205 - 218

Dew, I. T., \& Cabeza, R. (2011). The porous boundaries between explicit and implicit memory: behavioral and neural evidence. Annals of the New York Academy of Sciences 1224(1): 174-190

Döhring, J., Stoldt, A., Witt, K., Schönfeld, R., Deuschl, G., Born, J., \& Bartsch, T. (2017). Motor skill learning and offline-changes in TGA patients with acute hippocampal CA1 lesions. Cortex, 89: 156-168.

Duss, S. B., Reber, T. P., Hänggi, J., Schwab, S., Wiest, R., Müri, R. M., Brugger, P., Gutbrod, K., ... Henke, K. (2014). Unconscious relational encoding depends on hippocampus. Brain: a journal of neurology, 137(Pt 12), 3355-70.

Eichenbaum, H. \& Cohen, N. J. (2014). Can we reconcile the declarative memory and spatial navigation views on hippocampal function? Neuron, 83(4): 764-70.

Fantl, J. (2008). Knowing-how and knowing-that. Philosophy Compass. 3(3): 451-470.

Fernandez, G. \& Tendolkar, I. (2006). The rhinal cortex: 'gatekeeper' of the declarative memory system. Trends in Cognitive Science, 10(8): 358-62.

Foerde, K., Race, E., Verfaellie, M., \& Shohamy, D. (2013). A role for the medial temporal lobe in feedback-driven learning: Evidence from amnesia. Journal of Neuroscience, 33, 5698-5704.

Fridland, E. (2017). Skill and motor control: intelligence all the way down. Synthese, 174(6): 1539-1560

Gabrieli, J. D. E., Fleischman, D. A., Keane, M. M., Reminger, S. L., \& Morrel, F. (1995). Double dissociation between memory systems underlying explicit and implicit memory in the human brain. Psychological Science, 6(2): 72-82.

Gabrieli, J. D. E. (1998). Cognitive neuroscience of human memory. Ann. Rev. Psychol. 49(1): 87-115.

Gauthier, I., Tarr, M. J., Anderson, A. W., Skudlarski, P., \& Gore, J. C. (1999). Activation of the middle fusiform "face area" increases with expertise in recognizing novel objects. Nature Neuroscience, 2, 568573

Glick, E. (2011). Two methodologies for evaluating intellectualism. Philosophy and Phenomenological Research, 83(2): 398 - 434.

Glick, E. (2015) Practical modes of presentation. Nous, 49(3): 538-559.

Glisky, E. L., Schacter, D. L. \& Tulving, E. (1986) Computer learning by memory-impaired patients: acquisition and retention of complex knowledge. Neuropsychologia. 24: 313-28.

Graf, P., Squire, L. R., \& Mandler, G. (1984.) The information that amnesic patients do not forget. Journal of Experimental Psychology: Learning, Memory, and Cognition, 10, 164-178. 
Hannula, D. E., Tranel, D., \& Cohen, N. J. (2006). The long and the short of it: relational memory impairments in amnesia, even at short lags. The Journal of Neuroscience, 26: 8352-9.

Hannula, D. E. \& Ranganath, C. (2008). Medial temporal lobe activity predicts successful relational memory binding. The Journal of Neuroscience. 28: 116-24

Hardwick, R. M., Rottschy, C., Miall, R. C., \& Eickhoff, S. B. (2013). A quantitative meta-analysis and review of motor learning in the human brain. NeuroImage, 67, 283-297

Hartley, T., Bird, C. M., Chan, D. , Cipolotti, L., Husain, M. , Vargha-Khadem, F. and Burgess, N. (2007), The hippocampus is required for short-term topographical memory in humans. Hippocampus, 17: 34-48.

Hassabis, D., Kumaran, D., Vann, S. D., \& Maguire E. A. (2007). Patients with hippocampal amnesia cannot imagine new experiences. Proceedings of the National Academy of Sciences of the United States of America. 104: 1726-31.

Henke, K. (2010). A model for memory systems based on processing modes rather than consciousness. Nat Rev Neurosci.11(7):523-32

Heyselaar, E., Segaert, K., Walwoort, S. J. W., Kessels, R. P. C., \& Hagoort, P. (2017). The role of nondeclarative memory in the skill for language: Evidence from syntactic priming in patients with amnesia. Neuropsychologia, 101: 97-105.

Holdstock, J. S., Mayes, A. R. et al. (2002). Under what conditions is recognition spared relative to recall after selective hippocampal damage in humans? Hippocampus, 12(3): 341-51.

Hornsby, J. (2017) Knowing How in Philosophy of Action. Royal Institute of Philosophy Supplement, 80: 87-104.

Jacoby, L. L. \& Dallas, M. (1981) On the relationship between autobiographical memory and perceptual learning. J. Exp. Psychol. G. 110(3)Ñ 306-340.

Kime, S. K., Lamb, D. G., \& Wilson, B. A. (1996). Use of a comprehensive programme of external cueing to enhance procedural memory in a patient with dense amnesia. Brain Injury, 10(1), 17-25.

Knowlton, B. J., Mangels, J. A., \& Squire, L.R. (1996) A neostriatal habit learning system in humans. Science 273, 1399-1402.

Laurita, A. C. \& Spreng, R. N. (2017). The hippocampus and social cognition. In D.E. Hannula \& M.C. Duff (Eds). Hippocampus from Cells to Systems: Structure, Connectivity, and Functional Contributions to Memory and Flexible Cognition. New York: Springer, pp. 537-538.

Lee A. C., Yeung L. K., \& Barense M. D. (2012) The hippocampus and visual perception. Frontiers in Human Neuroscience. 6: 91.

Levy, N. (2017). Embodied savoir faire: knowledge-how requires motor representations. Synthese, 194(2): $511-530$.

Lewis, D. (1979). Attitudes De Dicto and De Se. Philosophical Review, 88: 513-543.

MacKay D. G., Stewart R., \& Burke D. M. (1998). H.M. revisited: relations between language comprehension, memory, and the hippocampal system. Journal of Cognitive Neuroscience. 10: 377-94.

McCormick, C., Rosenthal, C.R., Miller, T.D., Maguire, E.A. (2018). Mind-Wandering in People with Hippocampal Damage. Journal of Neuroscience, 38 (11) 2745-2754.

Michaelian, K. \& Sutton, J. (2017). Memory. Stanford Encyclopedia of Philosophy.

Milner, B. (1960). Impairment of visual recognition and recall after right temporal lobectomy in man. First Annual Meeting of the Psychonomic Society.

Milner, B. (1962). Les troubles de la memoire accompagnant des lesions hippocampiques bilaterales. Physiologie de l'hippocampe. Paris: CNRS. 
Milner, B. (1963). Effects of Different Brain Lesions on Card Sorting: The Role of the Frontal Lobes. Archives of Neurology. 9: 90-100

Milner, B. (1965) Visually-guided maze learning in man: Effects of bilateral hippocampal, bilateral frontal, and unilateral cerebral lesions Neuropsychologia. 3: 317-338.

Milner, B., Corkin, S., \& Teuber, H. L. (1968). Further analysis of the hippocampal amnesic syndrome: 14year follow-up study of H.M. Neuropsychologia. 6: 215-234.

Moscovitch, M. (1982). Multiple dissociations of function in amnesia. In Human Memory and Amnesia, L. S. Cermak (Editor). Erlbaum, Hillsdale, NJ, 1982.

Mullally, S. L. \& Maguire, E. A. (2014) Counterfactual thinking in patients with amnesia. Hippocampus. 24: 1261-6

Nadel, L. \& Moscovitch, M. (1997). Memory consolidation, retrograde amnesia and the hippocampal complex. Current Opinion in Neurobiology. 7: 217-27.

O'Kane G., Kensinger E. A., \& Corkin S. (2004) Evidence for semantic learning in profound amnesia: an investigation with patient H.M. Hippocampus. 14: 417-25

Olson, I.R., Page, K., Moore, K.S., Chatterjee, A., \& Verfaellie, M. (2006). Working memory for conjunctions relies on the medial temporal lobe. Journal of Neuroscience, 26(17): 4596-4601.

Pavese, C. (2015a). Knowing a rule. Philosophical Issues. 25(1): 165-188.

Pavese, C. (2015b). Practical senses. Philosophers' Imprint. 15(29): 1-25.

Pavese, C. (2018). Know-How, Action, and Luck. Synthese. 1-23.

Pavese, C. (In press). The psychological reality of practical representation. Philosophical Psychology.

Poldrack, R. A., Desmond, J. E., Glover, G. H., \& Gabrieli, J.D.E. (1998). The neural basis of visual skill learning: An fMRI study of mirror reading. Cerebral Cortex, 8, 1-10

Poldrack, R. A., Clark, J., Pare-Blagoev, J., Shohamy, D., Creso Moyano, J., Myers, C., \& Gluck, M. A. (2001). Interactive memory systems in the human brain. Nature, 414, 546-550.

Ranganath, C. \& Blumenfeld, R. S. (2005). Doubts about double dissociations between short- and longterm memory. Trends in Cognitive Sciences. 9: 374-80.

Reder, L.M., Park, H., \& Kieffaber, P.D. (2009). Memory systems do not divide on consciousness: Reinterpreting memory in terms of activation and binding. Psychological Bulletin, 135(1): 23-49.

Ribot, T. (1881). Les maladies de la mémoire, London: Kegan Paul, Trench \& Co. Paris: Alcan

Rossell, S. L., Price, C. J., \& Nobre, A. C. (2003). The anatomy and time course of semantic priming investigated by fMRI and ERPs. Neuropsychologia, 41(5): 550-64.

Roy, S. \& Park, N. W. (2010). Dissociating the memory systems mediating complex tool knowledge and skills. Neuropsychologia, 48(10): 3026 - 3036.

Ryan, L., Cox, C., Hayes, S.M., \& Nadel, L. (2008). Hippocampal activation during episodic and semantic memory retrieval: comparing category production and category cued recall. Neuropsychologia. 46: 21092121.

Ryle, G. (1945/1946). Knowing how and knowing that. Proceedings of the Aristotelian Society, 46: 1-16.

Ryle, G. (1949). The concept of mind. London: Hutchinson

Schacter, D. L., Chiu, C. Y. P., \& Ochsner, K. N. (1993). Implicit memory: A selective review. Annual Review of Neuroscience, 16, 159-182. 
Schapiro, A.C., Gregory, E., Landau, B., McCloskey, M., \& Turk-Browne, N.B. (2014). The necessity of the medial temporal lobe for statistical learning. J Cogn Neurosci 26:1736-1747.

Schendan, H.E., Searl, M.M., Melrose, R.J., \& Stern, C.E. (2003). An fMRI Study of the Role of the Medial Temporal Lobe in Implicit and Explicit Sequence Learning. Neuron. 37(6): 1013 - 1025

Scoville, W.B. \& Milner, B. (1957). Loss of recent memory after bilateral hippocampal lesions. Journal of Neurology, Neurosurgery, and Psychiatry. 20: 11-21

Schmolck H., Kensinger E. A., Corkin S., \& Squire L. R. (2002). Semantic knowledge in patient H.M. and other patients with bilateral medial and lateral temporal lobe lesions. Hippocampus. 12: 520-33

Skinner, E. I., \& Fernandes, M. A. (2007). Neural correlates of recollection and familiarity: a review of neuroimaging and patient data. Neuropsychologia, 45(10): 2163-79.

Squire, L. R. (1988). The organization and neural substrates of human memory. International Journal of Neurology, 22, 218-222,

Squire, L. R. (1986). Mechanisms of memory. Science, 232: 1612-1619.

Squire, L.R., Cohen, N.J., \& Zouzounis, J.A. (1984). Preserved memory in retrograde amnesia: Sparing of a recently acquired skill. Neuropsychologia, 22: 145-152.

Squire, L. R. \& Zola-Morgan, S. (1988). Memory: Brain Systems and Behavior. Trends in Neuroscience, $11,170-175$

Squire, L. R. \& Zola-Morgan, S. (1991). The medial temporal lobe memory system. Science, 253: 13801386.

Squire, L. R. (2004). Memory Systems of the Brain: A brief history and current perspective. Neurobiology of Learning \& Memory: 82, 171-177,

Squire, L. R. (1992). Memory and the hippocampus: A synthesis from findings with rats, monkeys, and humans. Psychological Review: 99, 195-231.

Stanley, J. \& Williamson, T. (2001). Knowing how. Journal of Philosophy, 98(8): 411-444.

Stanley, J. (2011a). Know How. Oxford: Oxford University Press.

Stanley, J. (2011b). Knowing (How). Nous, 45(2): 207-238.

Stanley, J., \& Krakauer, J. W. (2013). Motor skill depends on knowledge of facts. Front. Hum. Neurosci. 7:503.

Sullivan, E. V. \& Sagar, H. J. (1991). Double dissociation of short-term and long-term memory for nonverbal material in Parkinson's disease and global amnesia. A further analysis. Brain, 114(2): 893-906.

Sun, R., Merrill, E., \& Peterson, T. (2001). From implicit skills to explicit knowledge: A bottom-up model of skill learning. Cognitive Science, 25, 203-244.

Talmi, D., Grady, C. L., Goshen-Gottstein, Y., \& Moscovitch, M. (2005). Neuroimaging the serial position curve. Psychol. Sci.16:716-723.

Tranel, D., Damasio, A.R., Damasio, H., Brandt, J.P. (1994). Sensorimotor Skill Learning in Amnesia: Additional Evidence for the Neural Basis of Nondeclarative Memory. Learning and Memory, 1:165-179.

Tulving, E. (1985). How many memory systems are there? American Psychologist, 40(4): 385-398.

Tulving, E. \& Schacter, D. L. (1990). Priming and human memory systems. Science, 247, 301-306.

Vargha-Khadem, F., Gadian, D. G., Watkins, K. E., Connelly, A., Van Paesschen, W., \& Mishkin, M. (1997). Differential effects of early hippocampal pathology on episodic and semantic memory. Science, 277(5324): 376-380. 
Verfaellie, M., Croce, P., \& Milberg, W. P. (1995) The Role of Episodic Memory in Semantic Learning: An Examination of Vocabulary Acquisition in a Patient with Amnesia due to Encephalitis Neurocase. 1: 291-304.

Vermeulen, J. \& Aldenkamp, A. P. (1995). Cognitive side-effects of chronic antiepileptic drug treatment: A review of 25 years of research. Epilepsy Research, 22: 65-95.

Voss, J. L. \& Federmeier, K. D. (2011). FN400 potentials are functionally identical to N400 potentials and reflect semantic processing during recognition testing. Psychophysiology, 48(4): 532-46.

Wagner, A. D., Koutstaal, W., Maril, A., Schacter, D. L., \& Buckner, R. L. (2000). Task-specific priming in left inferior frontal cortex. Cerebral Cortex, 10, 1176-1184.

Wallis, C. (2008). Consciousness, context, and know-how. Synthese, 160.1: 123 - 153.

Warrington, E.K., \& McCarthy, R.A. (1988) The fractionation of retrograde amnesia. Brain. Cogn. 7(2): 184-200.

Warrington, E. K., \& Weiskrantz, L. (1974). The effect of prior learning on subsequent retention in amnesic patients. Neuropsychologia 12, 419-428, 1974.

Warrington, E. K. \& Shallice, T. (1969). The selective impairment of auditory verbal short-term memory. Brain, 92: 885-896.

Wechsler, D. (1945). A standardized memory scale for clinical use. J. of Psychol. 19: 87-95.

Weldon, M. S., \& Roediger, H. L., III (1987). Altering retrieval demands reverses the picture superiority effect. Memory and Cognition 15(4), 269-280.

Yamashita, H. (1993). Perceptual-motor learning in amnesic patients with medial temporal lobe lesions. Percept Mot Skills. 77(3 Pt 2):1311-4. 
Figure 1: Standard Model of Memory. Adapted from Squire, 1992.

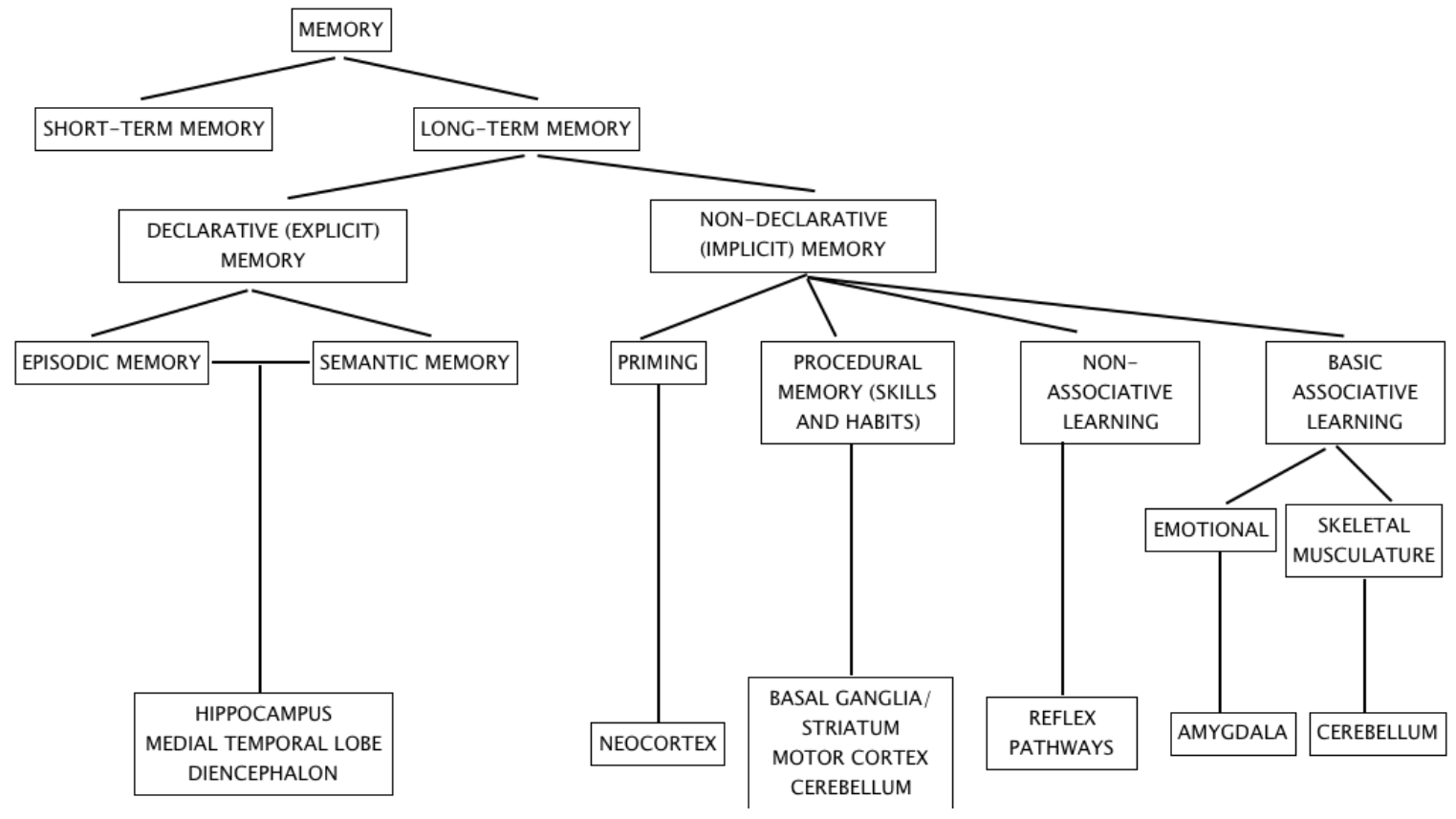


Figure 2: Results from H.M. vs controls' performance in two motor-skill learning tasks, from Corkin 1968. A) Mean-time on target during the Rotary Pursuit task as a function of session/day. B) Mean-number of contacts with the target during the Rotary Pursuit task as a function of session/day. C) Mean-time on target during Bimanual Tracking as a function of session/day. D) Contact-scores during Bimanual Tracking as a function of session/day.
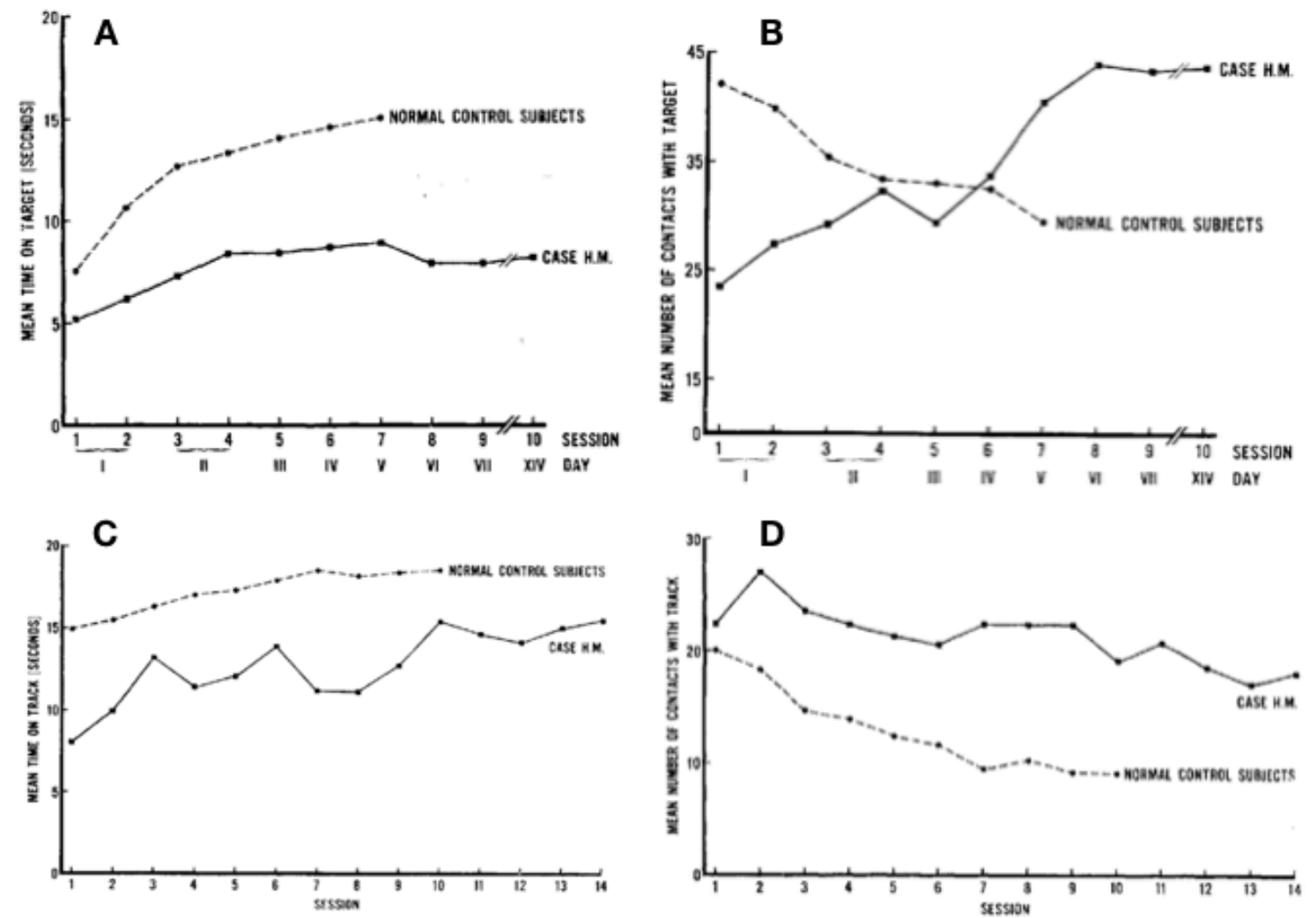
Figure 3: Results from D.A. vs controls' performance in the novel tools task, from Roy and Park, 2010. A) Mean completion time in the use-to-command test. B) Percent correct in the use-to-command test. C). Percentage of correct responses in recall of functional associative information by test trial. D) Mean completion time during training sessions across stages. Error bars indicate SEM.
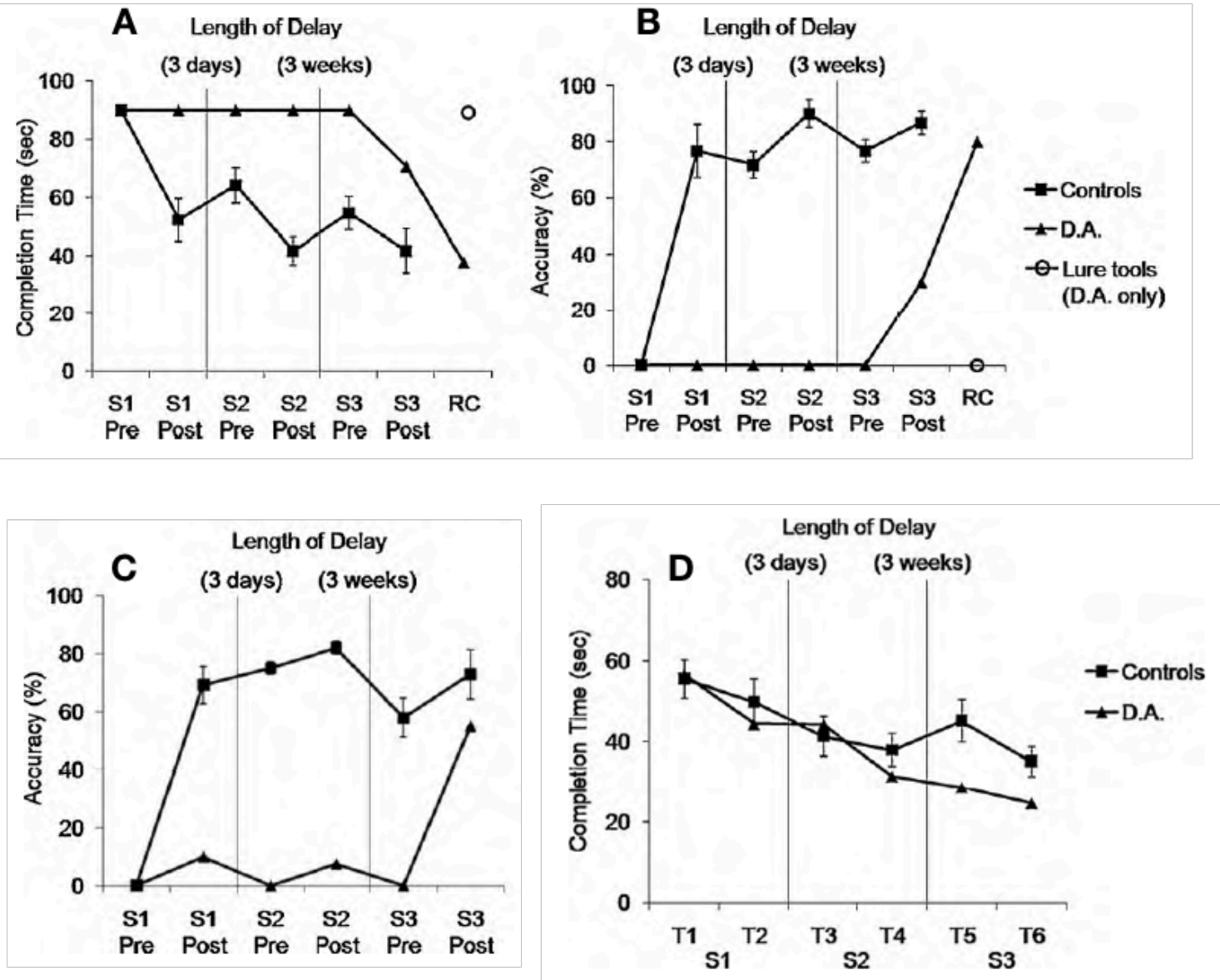